\title{
Surface-tailored graphene channels
}

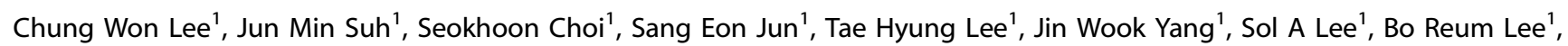 \\ Donghyeon Yoo ${ }^{2}$, Soo Young Kim (10) ${ }^{3 凶}$, Dong Sung Kim $\mathbb{B}^{2 凶}$ and Ho Won Jang $\mathbb{B}^{1 凶}$
}

The detection of ions and molecules in liquids has been receiving considerable attention for the realization of the electronic tongue. Solution-gated field-effect transistors (SFETs) with high sensitivity are useful for detecting ions and molecules by reading electrical transconductance. However, to date, ionic and molecular sensors that employ SFETs have limitations, such as the lack of a dynamic on-off function and low selectivity. In this study, we evaluate rationally designed graphene SFETs as pH and glucoseselective sensors. The integration of the microfluidic channel to the graphene SFET exhibits dynamic on-off functions by controlling injection and withdrawal of solutions. The graphene SFET device exhibits high pH and glucose selectivity when coated with Nafion as a molecular sieve and Au-decorated nanoparticles as receptors, respectively. The dynamic on-off functions and high selectivity of SFETs with tailored graphene channels have a high potential for advancing as a platform for electronic tongues by integrating the separate SFETs as an array for simultaneous sensing of multiple targets.

npj 2D Materials and Applications (2021)5:39; https://doi.org/10.1038/s41699-021-00223-2

\section{INTRODUCTION}

Recently, the desire for delicious food has led to considerable interest in authentic recipes. To actualize perfect recipes, information of the ingredients, such as their freshness, nutrition facts, and absolute taste is significant. Moreover, because of the "COVID-19" pandemic, people prefer cooking at home to eating out, eventually boosting the demand for authentic recipes ${ }^{1}$. Despite the increased demand for fresh and better-tasting food, consumers only depend on fragmentary nutrition information provided by the manufacturer and cannot estimate the actual taste of food. In addition, to actualize authentic recipes from prominent chefs, real-time monitoring sensors that detect absolute taste and possess prominent standards are required rather than relying on personal relative taste. Traditional electronic tongues are unsuitable for monitoring the taste and freshness of food in real time because of their high cost and portability issues. To actualize authentic recipes, the developed electronic tongue must have functions of absolute taste monitoring in real time. Therefore, the development of a low-cost, simple, miniaturized, high-performance electronic tongue is crucial to address the desire for better-tasting food and authentic recipes.

The choice of materials for the electronic tongue is vital, because it influences the performance of the sensor unit ${ }^{2}$. The performance of the electronic tongue is evaluated by the detection of small changes of the concentration of particular ions and molecules ${ }^{2}$. Lipid membranes ${ }^{3}$, conducting polymers ${ }^{4-6}$, metallic electrodes ${ }^{7}$, and two-dimensional (2D) materials $s^{8,9}$ are representative candidates to be used for the electronic tongue. Above all, many studies have been conducted on sensing applications of ionic and molecular species using 2D materials, such as graphene, $\mathrm{MoS}_{2}$, and other transitional metal dichalcogenides because of various reasons $s^{8,10}$. The physical and chemical properties of $2 \mathrm{D}$ materials make them suitable for application in sensing devices. The $2 \mathrm{D}$ materials have high sensitivity to the target materials because of their high surface-area-to-volume ratio ${ }^{8}$. Moreover, minimized device fabrication is possible because of their flexibility, strong mechanical strength, and transparency ${ }^{11}$. In particular, graphene has features that are different from those of other 2D materials. For instance, graphene possesses a semimetallic feature because of a zero bandgap ${ }^{12}$ and graphene SFETs exhibit bipolar characteristics in their conductivity properties ${ }^{13}$. These advantages of $2 \mathrm{D}$ materials differentiate from other candidates and leads to the possibility of developing a low-cost, simple, miniaturized, high-performance electronic tongue.

Various ionic and molecular sensors using 2D materials are developed, yet they have limitations, such as lack of a dynamic on-off function and low selectivity. Previous studies on ionic and molecular sensors including $\mathrm{pH}$ and glucose sensors presented one-sided step-like amperometric graphs ${ }^{14,15}$. These data sets do not have a standard or base resistance/current for comparison, because the injected solution cannot be ejected from the device. Reliability and repeatability are also essential factors as well as high sensitivity and selectivity to satisfy the sensor conditions. However, existing amperometric data graphs have a one-sided upward or downward shape, which indicates that the data lack reliability and repeatability. This monotonic increase or decrease of conductivity or resistance from amperometric data is caused by the successive addition of the next solution without discharging the previous one. When the next solution flows into the device without a discarding process, the base current is not consistent; it fluctuates. There must be a base current to have reliability and repeatability. This can be achieved by discarding the previous solution while injecting a washing solution, such as deionized water (DI) or $\mathrm{NaOH}$. The target solvent should be dissolved in an identical solution or electrolyte that becomes the washing solution. The integration of a microfluidic channel with the interdigitated electrode (IDE) leads to simultaneous/repetitive injection and withdrawal of solutions. The simultaneous/repetitive injection and withdrawal of the target and washing solutions will alternatively create a response current and base current, resulting in dynamic on-off functions. The dynamic on-off functions lead to the possibility of real time detection of the ionic or molecular

\footnotetext{
${ }^{1}$ Department of Materials Science and Engineering, Research Institute of Advanced Materials, Seoul National University, Seoul 08826, Republic of Korea. ${ }^{2}$ Department of Mechanical Engineering, Pohang University of Science and Technology (POSTECH), Pohang 37673, Republic of Korea. ${ }^{3}$ Department of Materials Science and Engineering, Korea

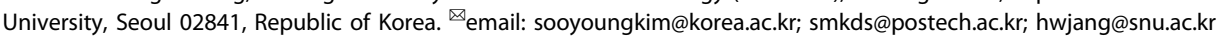



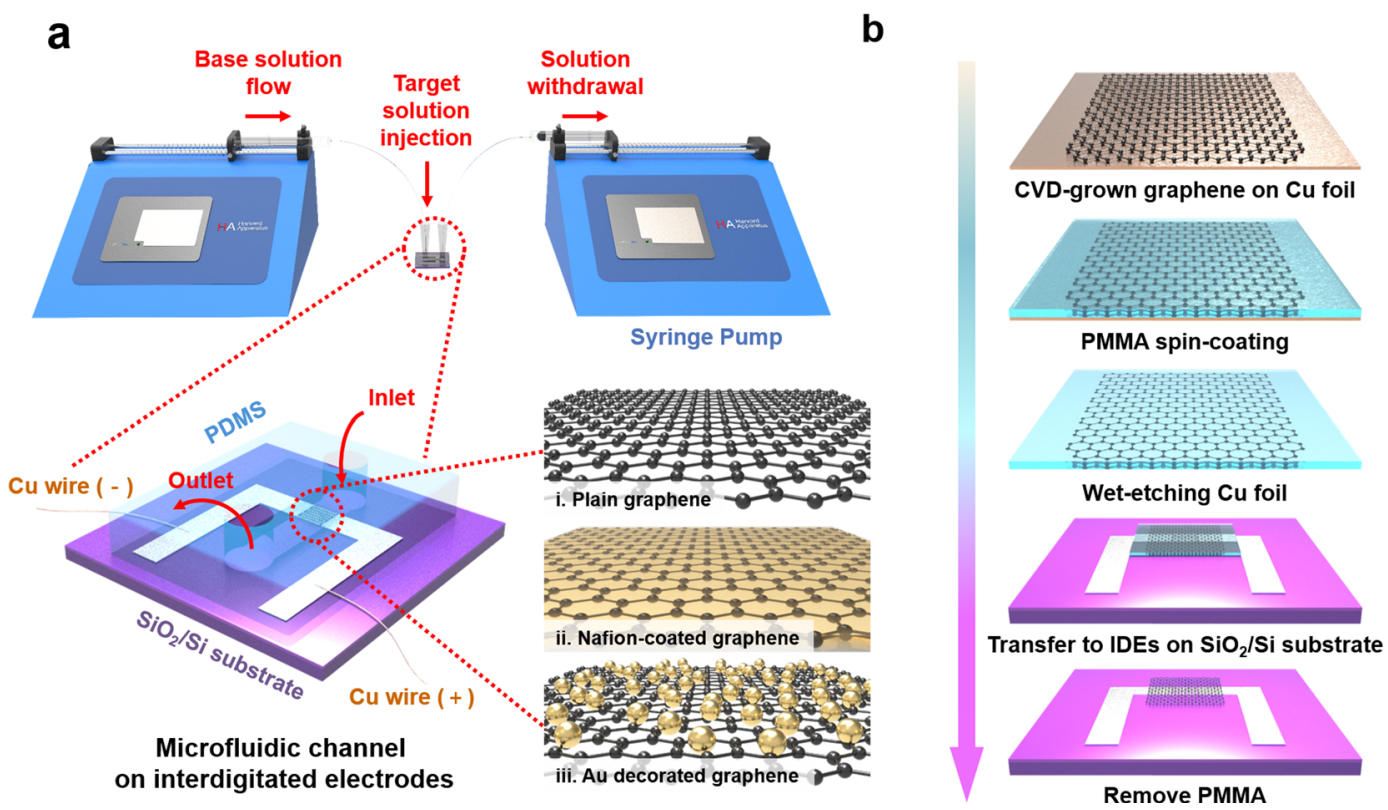

Fig. 1 Schematic of the overall experiment and sample fabrication. a Schematic diagram of the device; syringe pump for injection and withdrawal of solutions, microfluidic channel-attached interdigitated electrodes, pristine graphene, Nafion-coated graphene, and Audecorated graphene. b Sample fabrication illustration of CVD graphene synthesis.

species by comparing the response and base current as the solution flows through the device. In conclusion, the integration of a microfluidic channel with the IDE results in simultaneous/ repetitive injection and withdrawal of the solution. This provides dynamic on-off functions, leading to real time detection of target solutions resulting in reliability and repeatability of the device.

To solve selectivity issues from previous studies, we develop ionic and molecular sensors based on graphene that are highly responsive to $\mathrm{H}^{+}$and glucose molecules, using a one-step coating or decoration. According to our study, the Nafion film selectively allows small cations to penetrate through the film and the $\mathrm{Au}$ nanoparticles to enhance glucose sensitivity.

Beverages and chemicals, such as $\mathrm{pH}$ and glucose solutions, were used for the performance evaluation of the device. Furthermore, the beverage measurement data were evaluated using principal component analysis (PCA) to distinguish the drinks. The results demonstrated that Nafion-coated and Au-decorated graphenes are capable of selectively detecting $\mathrm{H}^{+}$and glucose molecules. Moreover, the possibility of differentiating real beverages demonstrates the potential for application as a taste sensor.

\section{RESULTS}

\section{Sensor design}

Pristine graphene was first transferred to an IDE by the chemical vapor deposition (CVD) process. The transferred graphene samples were classified into three groups: pristine graphene, Nafion-coated graphene, and Au-decorated graphene. The overall setup with syringe pumps for the injection and withdrawal of the target solutions and the patterned polydimethylsiloxane (PDMS)attached microfluidic channel system are illustrated in Fig. 1a. The CVD process for graphene transfer is depicted in Fig. $1 \mathrm{~b}$. Selectivity is achieved by modifying the surface through coating or decorating. Nafion-coated graphene is selective to $\mathrm{H}^{+}$, whereas Au-decorated graphene is selective to glucose molecules. The Nafion-coated film was fabricated by a one-step spin-coating process on CVD graphene. In contrast, Au decoration was performed on a different sample using an electron beam evaporator. Au is decorated on graphene with the morphology of distributed islands. Each island has a radius of $\sim 2 \mathrm{~nm}$, which is considered as nano-scaled. The decorated Au was very closely agglomerated into nanoparticles during evaporation, resulting in a very dense $\mathrm{Au}$ nanoparticle-decorated state. The Au decoration was confirmed by energy-dispersive X-ray spectroscopy (EDS) (Supplementary Fig. 1). As agglomeration occurs to minimize surface energy, the $\mathrm{Au}$ atoms merge to form a nano-sized particle $^{16}$. After the fabrication of the different IDEs, a channelpatterned PDMS was attached and the experiments were conducted. Two syringe pumps were then connected to the device for the liquid injection and withdrawal (Supplementary Fig. 2 ). The magnified scheme and real image of the microfluidic channel device illustrating the inlet and outlet of the solution are depicted in Fig. 2a.

\section{Analysis of pristine, Nafion-coated, and Au-decorated graphene}

The sensing properties are closely related to the existence and morphologies of the coating and decorating materials. Figure $2 b$ demonstrates that the experiments were conducted using proper graphene according to the Raman spectra ${ }^{17,18}$. Also, Nafion coating and Au decorating do not affect the graphene, as shown by the identical peak position and intensity ratio of the $G$ and $2 D$ peak. The images of the pristine graphene transferred on the IDE were obtained by optical microscopy (OM) (Fig. 2c) and those of the graphene transferred on the $\mathrm{Cu}$ grid were obtained by transmission electron microscopy (TEM) (Fig. 2f), which can be noticed from the wrinkles ${ }^{19}$. The inset indicates the selected area electron diffraction (SAED) patterns of the graphene. The polycrystalline rings of graphene $002,100,110$ were observed. An OM image of Nafion-coated graphene transferred and coated on the IDE is depicted in Fig. $2 \mathrm{~d}$ and a cross-sectional scanning electron microscopy (SEM) image is shown in Fig. $2 g$ to estimate the thickness of the Nafion-coated film ${ }^{20}$. The inset indicates the boundary of the film and $\mathrm{SiO}_{2}$. The bright region in the SEM image represents the film, which is uniformly covered with a thickness of $280 \mathrm{~nm}$ (Fig. 2g). In addition, it can be assumed that substances cannot penetrate through the density. The OM image of Audecorated graphene transferred and deposited on the IDE is shown in Fig. $2 e$ and the TEM image of the transferred and 

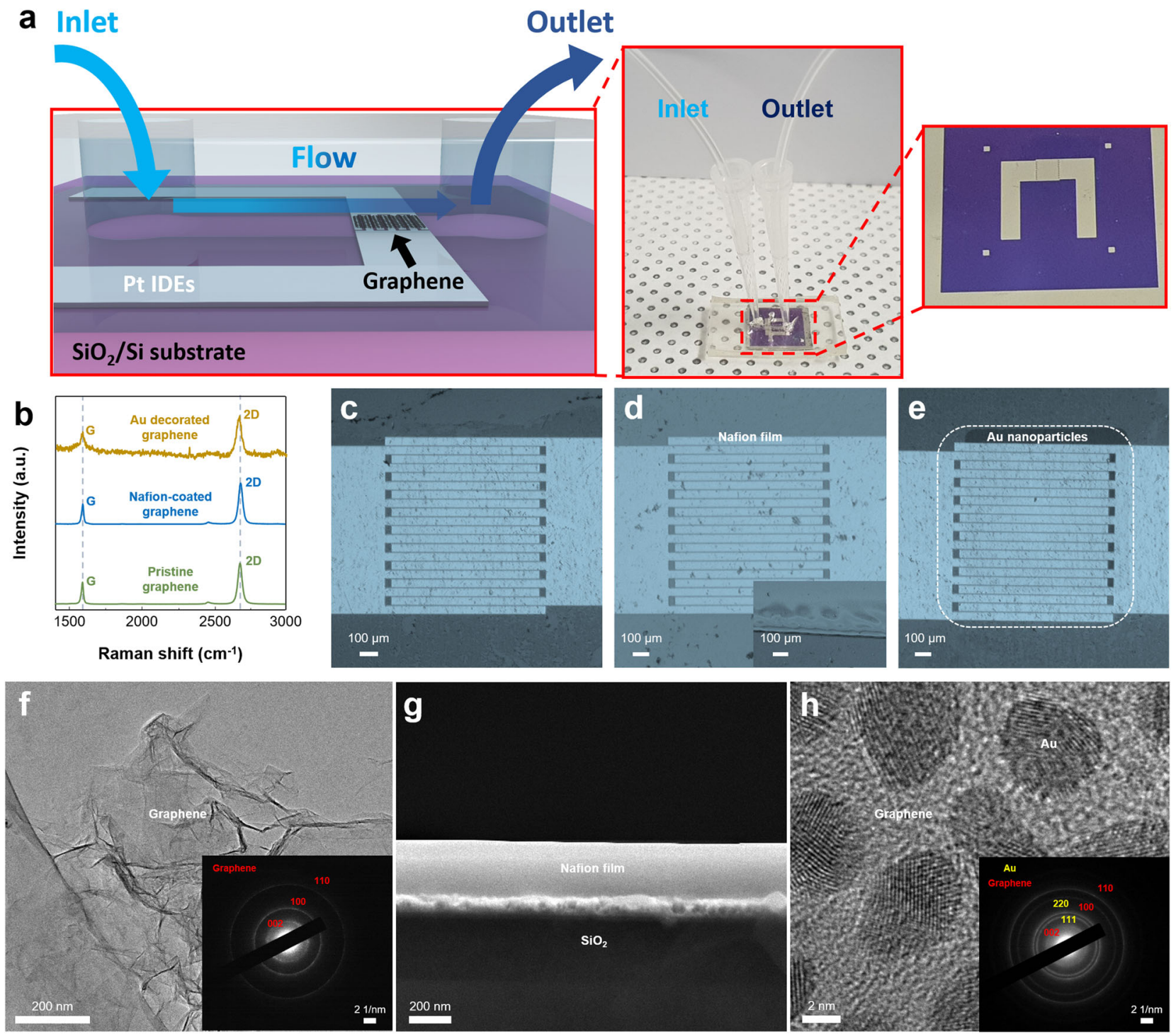

Fig. 2 Experimental setup and characterization of pristine, Nafion-coated, and Au-decorated graphene. a Magnified scheme and real image of the microfluidic channel device illustrating the inlet and outlet of the solution. $\mathbf{b}$ Raman spectroscopy of pristine, Nafion-coated, and Au-decorated graphene. The peaks show that the graphene is not influenced by Nafion coating or Au decoration. OM images of c pristine graphene, d Nafion-coated graphene, and e Au-decorated graphene. $\mathbf{f}$ TEM image of CVD grown pristine graphene. The inset shows the SAED patterns of pristine graphene. $\mathbf{g}$ Cross-sectional SEM image of Nafion-coated graphene. $\mathbf{h}$ TEM image of Au-decorated graphene. The inset shows the SAED patterns of Au-decorated graphene.

decorated sample on the Cu grid is displayed in Fig. $2 \mathrm{~h}$. The bright region represents graphene, whereas the $\mathrm{Au}$ nanoparticledecorated region is relatively dark. Because of the agglomeration during electron beam evaporation, the particles are packed like islands with a radius of $\sim 2 \mathrm{~nm}$. The inset displays the SAED patterns of the Au-decorated graphene. In addition to the ring of graphene 002, 100, 110, Au 111 and 220 were also observed ${ }^{21}$. Comparing the insets (SAED patterns) of Fig. $2 f, h$, we could confirm that $\mathrm{Au}$ was deposited on the graphene surface. Comparing Fig. $2 \mathrm{c}-\mathrm{e}$, the color of the $\mathrm{SiO}_{2}$ region of Fig. $2 \mathrm{c}$, e is dark blue, whereas that in Fig. $2 d$ is light blue. This difference is because of the presence of the Nafion film. From the lower part in the inset of Fig. $2 \mathrm{~d}$, the color is dark blue, displaying bare $\mathrm{SiO}_{2}$, the colors of which are identical to those in Fig. 2c, e. Figure $2 e$ is different from Fig. $2 c$, which has a black colored region in the IDE fingers, indicating that the Au was successfully decorated on the IDE active site.

\section{pH performances of the three types of SFETs}

The fundamental ion/molecule sensor is the $\mathrm{pH}$ sensor $\left(\mathrm{H}^{+}\right.$ sensor). The importance of precise hydrogen concentration detection cannot be stressed enough. The acidity of a substance may provide certain information, such as food spoilage, chemical analysis, and monitoring clean or wastewater ${ }^{22}$. Because of this, there have been numerous studies on $\mathrm{pH}$ sensors. However, this study introduces differentiated advantages. The sensing properties are related to the existence of the decoration or film to enhance the sensitivity or selectivity. Pristine, Nafion-coated, and Au-decorated graphene were exposed to various $\mathrm{pH}$ solution concentrations and compared (Fig. $3 a-c)$. Pristine graphene has a maximum $\mathrm{pH}$ response of seven times of the base current. The response increases as the $\mathrm{pH}$ concentration increases. The response enhancement by $\mathrm{pH}$ inclination is because of the conduction of $\mathrm{OH}^{-}$increases at a rate higher than that of $\mathrm{H}_{3} \mathrm{O}^{+23}$. In the case of the $\mathrm{pH}$ solutions, pristine and Nafion-coated graphene exhibit similar results, which indicates that the fact of 
a
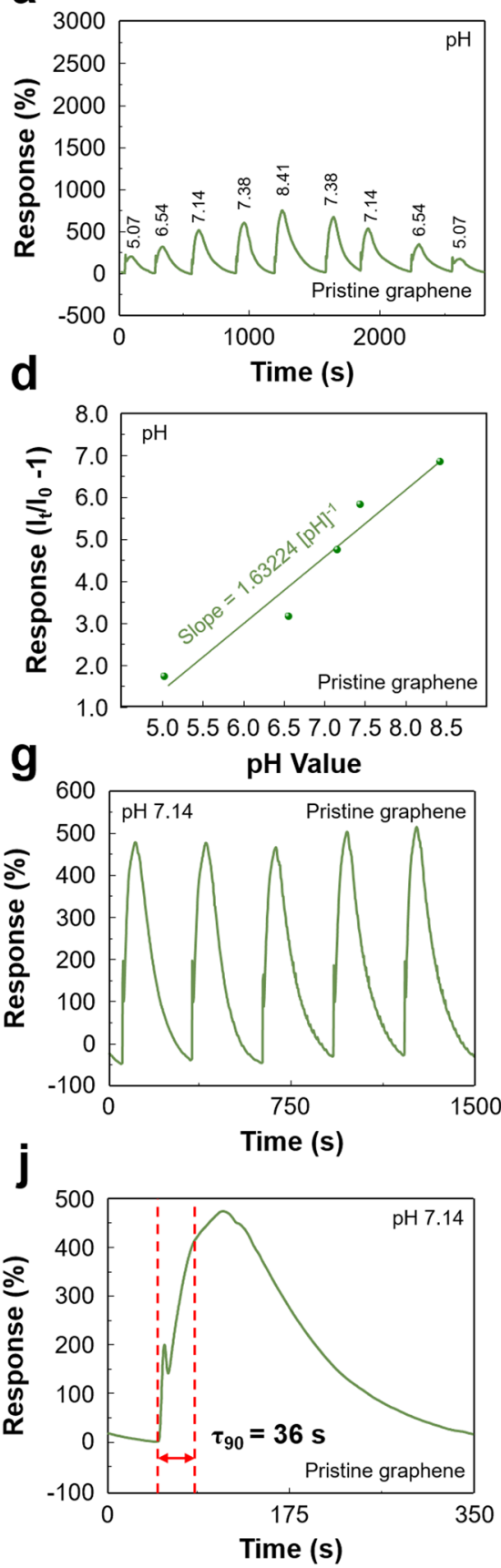

b
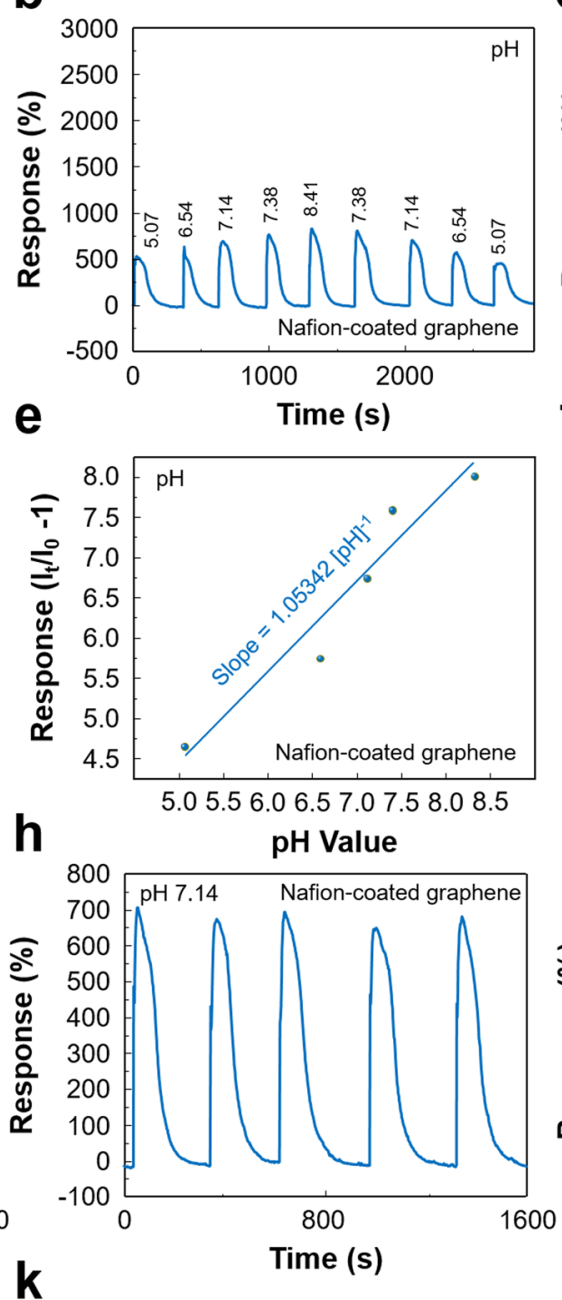

$\mathbf{K}$

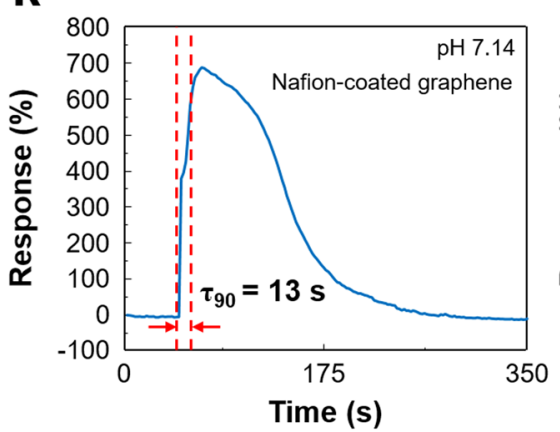

C
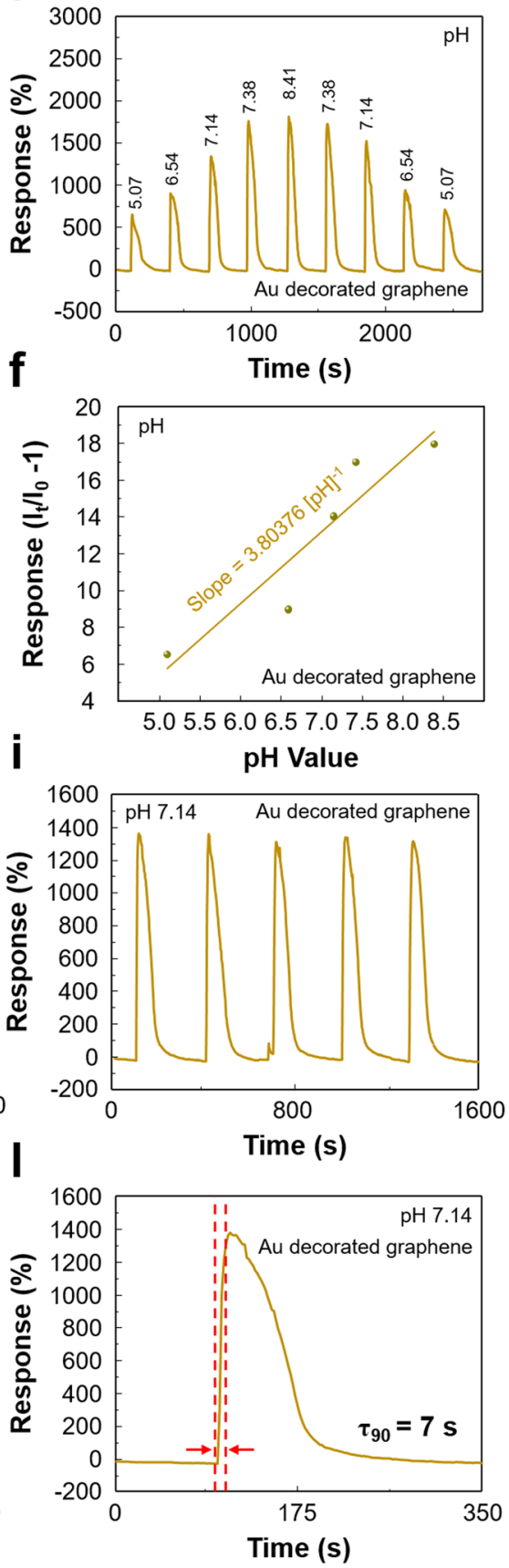

Fig. 3 pH detection characteristics of the graphene SFETs. pH detection of a pristine graphene, $\mathbf{b}$ Nafion-coated graphene, c Au-decorated graphene, and $\mathbf{d}$-f linearity of pristine graphene, Nafion-coated graphene, and Au-decorated graphene by pH value vs. response. Repetitive test of $\mathrm{pH} 7.14$ solution response of $\mathbf{g}$ pristine graphene, $\mathbf{h}$ Nafion-coated graphene, and $\mathbf{i}$ Au-decorated graphene. The $\tau_{90}$ values of response to $\mathrm{pH} 7.14$ solution of $\mathbf{j}$ pristine graphene, $\mathbf{k}$ Nafion-coated graphene, and I Au-decorated graphene.

$\mathrm{H}_{3} \mathrm{O}^{+}$ions hop through the Nafion film (Fig. 3a, b). The detailed mechanism of $\mathrm{H}_{3} \mathrm{O}^{+}$ions passing through the Nafion film will be discussed later. Also, Nafion-coated graphene does not respond to other larger molecules, such as glucose, uric acid, and ascorbic acid (Fig. $6 d-f$ ). This is because of the ability of the film to allow the penetration of cations and prevent other molecules from passing through $\mathrm{it}^{24}$. The film selectively allows the cations to permeate and filters other substances, acting as a molecular sieve. In contrast, Au nanoparticles have a catalytic effect on $\mathrm{H}^{+}$ions ${ }^{25}$, thereby increasing the response; however, they do not have selectivity to $\mathrm{H}^{+}$ions compared to glucose (Figs. $3 \mathrm{c}$ and $4 \mathrm{~b}$ ). All the three cases display a linear relationship between the response and $\mathrm{pH}$ value; the increase and decrease of the $\mathrm{pH}$ value have identical results with previous studies ${ }^{18,26,27}$ (Fig. 3d-f). The points in Fig. $3 d-f$ were determined by the average value of response for each $\mathrm{pH}$. As the $\mathrm{pH}$ increases or decreases, the $\mathrm{OH}^{-}$or $\mathrm{H}_{3} \mathrm{O}^{+}$ions gather to the surface of the graphene, resulting in a higher or lower response. The slopes are $1.63224[\mathrm{pH}]^{-1}, 1.05342[\mathrm{pH}]^{-1}$, $3.80376[\mathrm{pH}]^{-1}$, respectively. The three samples demonstrate reversibility and repeatability, exhibiting the same response to identical $\mathrm{pH}$ values after injecting another solution. Also, according to Fig. 3g-i, pristine, Nafion-coated, and Au-decorated 
a

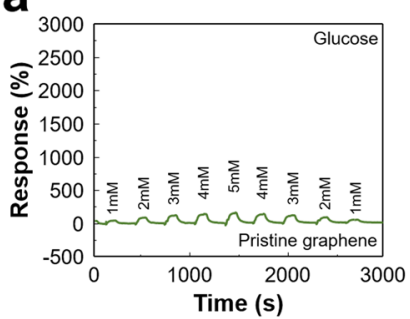

e

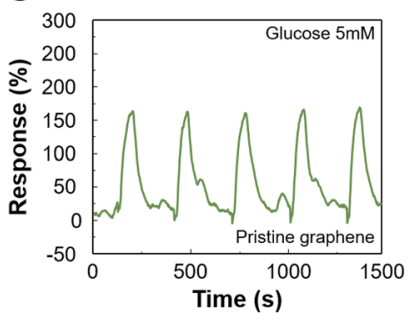

i

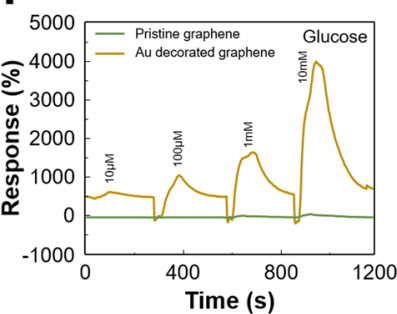

b

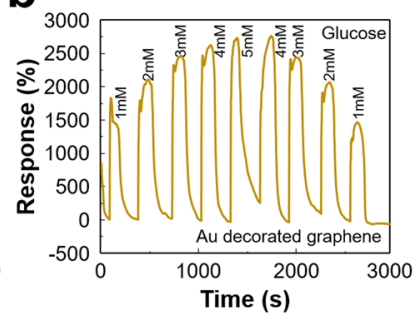

f

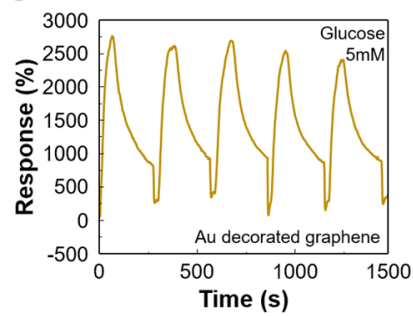

C

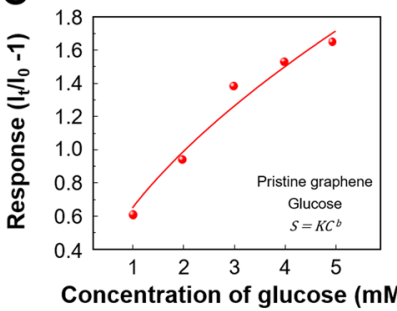

g

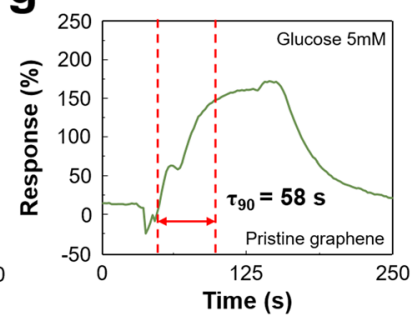

d

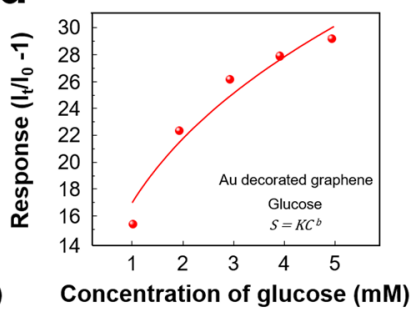

h

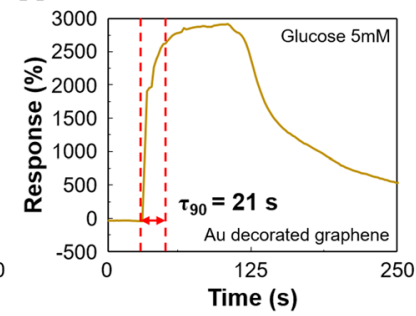

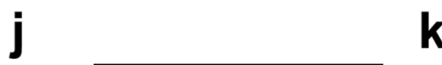
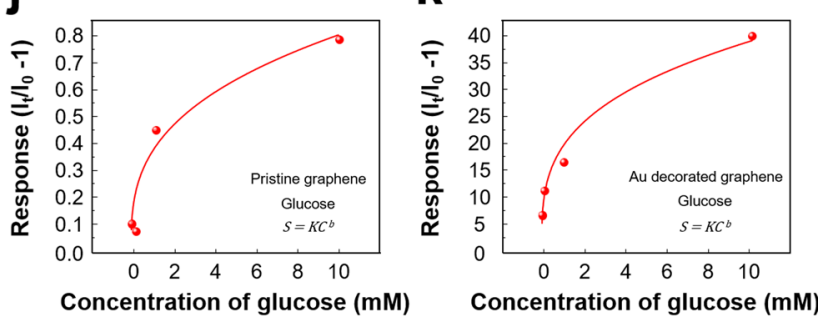

Fig. 4 Glucose detection characteristics of the graphene SFETs. Glucose detection responses using a pristine graphene and $\mathbf{b}$ Au-decorated graphene. Calibration of responses for c pristine graphene and d Au-decorated graphene to 1-5 mM of glucose plotted using Freundlich equation. Repetitive curves of response to $5 \mathrm{mM}$ glucose solution of e pristine graphene and $\mathbf{f}$ Au-decorated graphene. $\tau_{90}$ value of $\mathbf{g}$ pristine graphene and $\mathbf{h}$ Au-decorated graphene response to $5 \mathrm{mM}$ glucose solution. Detection limit measurements for $\mathbf{i}$ pristine and Au-decorated graphene. Calibration of responses for $\mathbf{j}$ pristine graphene, $\mathbf{k}$ Au-decorated graphene to $10 \mu \mathrm{M}-10 \mathrm{mM}$ of glucose plotted using Freundlich equation.

graphene display the same response to the repeatedly injected solution of $\mathrm{pH} 7.14$. The response values to a $\mathrm{pH}$ of 7.14 in Fig. $3 g-i$ were identical to those in Fig. 3a-c. This indicates the fact that the fabricated device is reliable as a $\mathrm{pH}$ sensor. The response time was also measured to verify the response speed of pristine, Nafion-coated, and Au-decorated graphene to pH (Fig. 3j-I). The response time is considered a crucial factor in the evaluation of sensors. The time taken to reach $90 \%$ saturation after applying the target material was considered for the response time assessment. The time taken to reach $90 \%$ of the saturation point is represented by $\tau_{90}$. At a pH of 7.14 , the $\tau_{90}$ of pristine graphene was $36 \mathrm{~s}$, whereas that of Nafion-coated graphene was $13 \mathrm{~s}$. The Audecorated graphene had the shortest time of $7 \mathrm{~s}$. The response time of Nafion-coated graphene is shorter than pristine graphene. This is due to the existence of the intermediate product in the $\mathrm{pH}$ solution. The $\mathrm{pH}$ solution used for the research is a mixture of $\mathrm{K}_{2} \mathrm{HPO}_{4}$ and $\mathrm{KH}_{2} \mathrm{PO}_{4}$ with various ratios. These $\mathrm{pH}$ solutions not only releases $\mathrm{H}_{3} \mathrm{O}^{+}$or $\mathrm{OH}^{-}$, but also has $\mathrm{K}^{+}, \mathrm{HPO}_{4}{ }^{-}, \mathrm{HPO}_{4}{ }^{2-}$ ions as intermediates, which acts as a competing ion when they become adjacent to the graphene surface According to other $\mathrm{pH}$ sensor researches, other ions have the possibility to interfere with the primary ion $\left(\mathrm{H}^{+}\right)$when the ions are mixed in a solution ${ }^{28-30}$. This interference causes competition between ions of forming a bond between graphene and the ions. Due to other studies, selective coefficients are calculated to evaluate the selectivity for $\mathrm{H}^{+}$against interfering ions. Among the representative cations $\left(\mathrm{Na}^{+}, \mathrm{K}^{+}, \mathrm{NH}_{4}^{+}, \mathrm{Ca}^{2+}, \mathrm{Mg}^{2+}\right), \mathrm{K}^{+}$has the highest value. This means that $\mathrm{K}^{+}$competes most with $\mathrm{H}^{+}$relatively to other cations. The
Nafion-coating process relatively prevents $\mathrm{K}^{+}$from being adjacent to the graphene surface than pristine graphene by selectively penetrating $\mathrm{H}^{+}$. Thus, the Nafion-coated graphene has less interference of $\mathrm{K}^{+}$than pristine graphene, showing faster response time. The comparison of $\mathrm{H}_{3} \mathrm{O}^{+}$and $\mathrm{OH}^{-}$dominant cases in the graphene SFETs is illustrated (Supplementary Fig. 3a). Acidic conditions involve the $\mathrm{H}_{3} \mathrm{O}^{+}$ions approaching the graphene SFET surface, thereby gathering electrons to the surface, which results in $n$-doping effects. In contrast, $\mathrm{OH}^{-}$dominant conditions eventually collect holes to the surface giving $p$-doping effects $^{23}$.

Table 1 compares various types of $\mathrm{pH}$ sensors using graphene. The most prominent distinction of this work from other studies is its reversibility using an on-off available microfluidic channel system. As the base current is consistent, an identical response is obtained at the same $\mathrm{pH}$ value regardless of the previous $\mathrm{pH}$ solution. Other studies have amperometric data; however, they exhibit a form of consistent increase or decrease in conductivity or resistance, i.e., the amperometric data form a stair-step graph ${ }^{26,27}$. In this case, the base current or resistance is ambiguous because of the absence of standard value. Also, the subsequent process is influenced by the former one. Without washing the active site with DI water or $\mathrm{NaOH}$ (washing solution), the target solution from the previous step would affect the next step, resulting in unreliable data. However, integrating the microfluidic channel with the IDE assures that the device is reliable as a sensor that provides repeatable and accurate data. 
Table 1. Comparison of other graphene-based $\mathrm{pH}$ sensors.

\begin{tabular}{|c|c|c|c|c|c|c|}
\hline Channel material & $\begin{array}{l}\mathrm{pH} \\
\text { detection span }\end{array}$ & Measurement method & $\begin{array}{l}\text { Response/recovery } \\
\text { time (s) }\end{array}$ & $\begin{array}{l}\text { Reversibility } \\
\text { (amperometric) }\end{array}$ & Sensitivity & Reference \\
\hline $\begin{array}{l}\text { Mechanically exfoliated } \\
\text { graphene }\end{array}$ & $4 \sim 10$ & Amperometric & $5 / 20$ & NA & NA & 26 \\
\hline $\begin{array}{l}\text { Mechanically exfoliated } \\
\text { graphene }\end{array}$ & $6 \sim 9$ & Transfer curves, amperometric & NA & Reversible & NA & 64 \\
\hline $\begin{array}{l}\text { Mechanically exfoliated } \\
\text { graphene }\end{array}$ & $4.0 \sim 8.2$ & Transfer curves, amperometric & $\sim 60 / \mathrm{NA}$ & NA & NA & 27 \\
\hline Graphene mesh & $6.55 \sim 8.25$ & Transfer curves & NA & NA & $7 \mathrm{mV} / \mathrm{pH}$ & 65 \\
\hline CVD graphene & $5.3 \sim 9.3$ & Transfer curves, amperometric & $\sim 10 / \sim 50$ & Reversible & $58.2 \mathrm{mV} / \mathrm{pH}$ & 66 \\
\hline CVD graphene & $4.3 \sim 8.4$ & Transfer curves, amperometric & $\sim 50 / \sim 100$ & Reversible & $22 \mathrm{mV} / \mathrm{pH}$ & 18 \\
\hline CVD graphene & $5.55 \sim 8.05$ & $\begin{array}{l}\text { Transfer curves, on-off available } \\
\text { sensing curves }\end{array}$ & $\sim 30 / \sim 100$ & Reversible & $\begin{array}{l}115.2 \mathrm{mV} / \mathrm{pH} \\
8.05: 450 \%\end{array}$ & Our work \\
\hline
\end{tabular}

\section{Glucose performances of the three types of SFETs}

The research field of glucose detection has been an attractive topic because of the emergence of healthcare for diabetes ${ }^{31}$. Many glucose-sensing studies were based on an enzyme called glucose oxidase for its high sensitivity and low detection limit ${ }^{32}$. However, this method is limited by the fact that the enzymes do not possess long-term stability and induce the intermediate production of $\mathrm{H}_{2} \mathrm{O}_{2}$, which interferes with the reaction ${ }^{32}$. Therefore, it is necessary to develop a type of glucose sensor with a long life term without using enzymes. This study focuses on a nonenzymatic glucose sensor with high sensitivity and sustainability, which uses graphene and Au nanoparticles to detect glucose. The responses of the three different samples were also measured with glucose solutions from 1 to $5 \mathrm{mM}$ (Figs. $4 \mathrm{a}, \mathrm{b}$ and $6 \mathrm{~d}$ ). Pristine graphene has a response of 1.7 times higher than the base current when exposed to $5 \mathrm{mM}$ glucose, whereas Au-decorated graphene has a response of $2926 \%$ in $5 \mathrm{mM}$ glucose, inferring that $\mathrm{Au}$ nanoparticles act as a receptor in glucose sensing (Fig. 4a, b). As previously explained, Nafion-coated graphene does not respond to glucose because of the effect of the film preventing glucose from adjoining with graphene (Fig. 6d). Both pristine and Audecorated graphene do not have linearity between the response and concentration of glucose. As the concentration increases, the response also increases, but the graphics follow the Freundlich adsorption isotherm. According to the Freundlich adsorption isotherm, the concentration of solutes being adsorbed onto the surface of solids has an empirical relationship with the concentration of the solute in the liquid ${ }^{33}$. Instead of increasing the response at a consistent rate, the inclination decreases with the increase of the solution concentration, resulting in an irrational function form of the response vs. concentration graph (Fig. 4c, d). The slope of the graph decreases as the concentration of the solution increases. The glucose molecules that were already adhered to the surface block the attachment of newly introduced molecules. The function variables $S$ and $C$ refer to the response and concentration, respectively. $K$ and $b$ are constant for a typical adsorbate and adsorbent at a specific temperature. The constant $b$ is the indicator of pressure; as $b$ approaches 0 , which indicates the adsorbent is under extremely high pressure conditions, the range of adsorption becomes irrelevant to pressure. However, $b$ approaching 1 indicates that the response and concentration have a linear relationship.

The selectivity of the Au-decorated graphene to glucose was evaluated by comparing the responses to other substances, such as ascorbic acid and uric acid (Fig. 4b and Supplementary Fig. 4b, d). The response of pristine graphene to ascorbic acid and uric acid was also evaluated to precisely analyze the selectivity issues (Supplementary Fig. 4a, c). The other glucose-targeted sensor researches tests used uric acid and ascorbic acid for selectivity tests ${ }^{34-36}$. The evaluation of pristine graphene and the Au-decorated graphene data, all cases with glucose, ascorbic acid, and uric acid, demonstrated that Au enhanced the selectivity to all substances. Due to the $\mathrm{Au}$ nanoparticles, uric and ascorbic acids do have response enhancement. However, comparing the response of the pristine graphene and the Au-decorated graphene, glucose has noticeable sensitivity enhancement. To be more specific, the response ratio of the Au-decorated graphene and the pristine graphene to $5 \mathrm{mM}$ of each solution (glucose, ascorbic acid, and uric acid) is significantly different (18.33:1 for glucose, 0.83 for ascorbic acid, and 7 for uric acid). In Fig. 4e, f, pristine and Au-decorated graphene exhibit identical responses to consecutive injection of $5 \mathrm{mM}$ glucose. Also, the response value of Fig. $4 \mathrm{e}, \mathrm{f}$ to $5 \mathrm{mM}$ glucose is the same as that of Fig. $4 a$, b. Therefore, the device demonstrates reliability and repeatability in terms of detecting glucose. Further, the results of the detection limit of pristine and Au-decorated graphene to glucose are shown in Fig. 4i, demonstrating conspicuous response differences. Au-decorated graphene can detect miniscule concentrations, such as 10 or $100 \mu \mathrm{M}$ glucose. However, pristine graphene has an extremely low response to 10 or $100 \mu \mathrm{M}$ glucose. Table 2 displays the differences between other glucose sensors and the sensor in this study. Various methods have been used for glucose sensing, including decorating metal nanoparticles such as $\mathrm{Cu}, \mathrm{Pt}, \mathrm{Au}$, and the formation of nanocomposites using chitosan ${ }^{35,37,38}$. As mentioned above, in contrast to the preceding researches ${ }^{35-37,39-41}$ displaying a monotonic increase or decrease in the amperometric data, which is influenced by the previous solution, the on-off system provides reliability in a sensor having a consistent response to the same concentration of glucose. Also, the device has high sensitivity that detects up to $10 \mu \mathrm{M}$, reversibility, and fast response/recovery time.

The response time for detecting glucose was for pristine and Au-decorated graphene. Similar to the case of $\mathrm{pH}$, the $\tau_{90}$ values of $5 \mathrm{mM}$ glucose for pristine and Au-decorated graphene are shown in Fig. $4 \mathrm{~g}, \mathrm{~h}$. The value of $\tau_{90}$ for pristine graphene was $58 \mathrm{~s}$, and that for Au-decorated graphene was $21 \mathrm{~s}$. Comparing these two results, it can be concluded that $\mathrm{Au}$ nanoparticles enhance the adhesion of glucose to graphene by acting as receptors. Figure $4 \mathbf{j}$, $\mathrm{k}$ displays the relationship between response and concentration ranging from $10 \mu \mathrm{M}$ to $10 \mathrm{mM}$. The results are identical from Fig. $4 c$, d, following the Freundlich relationship. The schematic illustrates the difference between pristine and Au-decorated graphene in detecting glucose (Supplementary Fig. 3b). As the glucose approaches the surface of SFET, it loses a hydrogen atom, which forms a bond with the surface resulting in an $n$-doping effect. The Au nanoparticles decorated at the top of the graphene acts as a receptor that facilitate the bonding of the glucose 


\begin{tabular}{|c|c|c|c|c|c|c|}
\hline $\begin{array}{l}\text { Cu nanoparticle-modified } \\
\text { graphene }\end{array}$ & $0.05 \sim 0.25$ & Amperometric & $\sim 2 / \mathrm{NA}$ & NA & NA & 35 \\
\hline $\begin{array}{l}\text { Graphene/AuNPs/chitosan } \\
\text { nanocomposites }\end{array}$ & $2 \sim 10$ & $\begin{array}{l}\text { Cyclic voltammograms, } \\
\text { amperometric }\end{array}$ & $\sim 10 / \mathrm{NA}$ & NA & $6 \mathrm{mM}: 3.2 \%$ & 38 \\
\hline CVD graphene & $0.1 \sim 10$ & Amperometric & $\sim 50 / \mathrm{NA}$ & NA & $\mathrm{N} / \mathrm{A}$ & 67 \\
\hline Au-decorated CVD graphene & $0.01 \sim 10$ & $\begin{array}{l}\text { Transfer curves, on-off } \\
\text { available sensing curves }\end{array}$ & $\sim 50 / \sim 125$ & Reversible & $\begin{array}{l}32 \mathrm{mV} / \mathrm{mM} \\
5 \mathrm{mM}: 2750 \%\end{array}$ & Our work \\
\hline
\end{tabular}

a

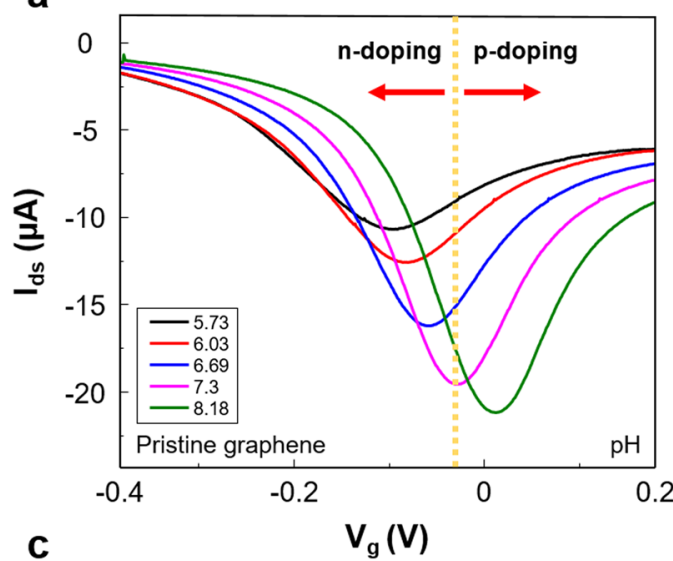

C

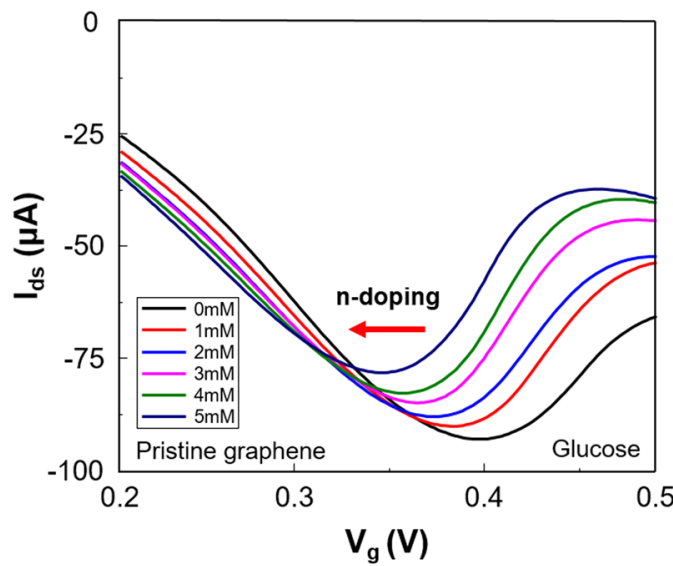

b
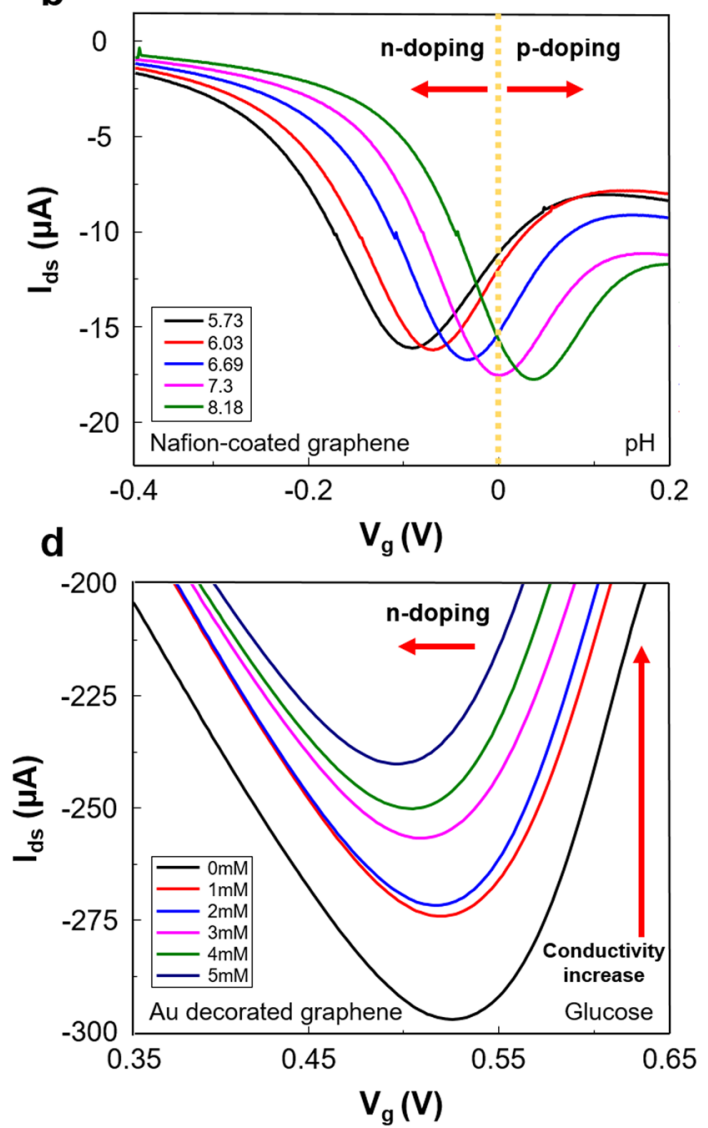

Fig. 5 Transfer characteristics of the graphene-based SFETs. $\mathrm{pH}$ transfer curves of a pristine graphene and $\mathbf{b}$ Nafion-coated graphene ranging from $\mathrm{pH} 5.73$ to 8.18 . Glucose transfer curves of $\mathbf{c}$ pristine graphene and $\mathbf{d}$ Au-decorated graphene ranging from 0 to $5 \mathrm{mM}$.

molecules with the $\mathrm{SFET}^{38}$. Therefore, the $n$-doping effect is more in the Au-decorated graphene SFET than in pristine graphene. As explained previously in the detection of $\mathrm{pH}$, the circumstances are also similar to those of the glucose detection. As the glucose concentration increases in the solution, the $n$-doping effect on the graphene increases. The glucose is oxidized when it approaches the surface of graphene and the detached hydrogen is adsorbed onto the graphene, thereby inducing $n$-doping effects on the graphene. The precise mechanism of this process will be explained later.

\section{Transfer characteristics of the three types of SFETs}

For further evaluation, the transfer characteristics in the response of pristine and Nafion-coated graphene to $\mathrm{pH}$ solutions were studied (Fig. 5a, b). The measurements were obtained by changing the gate voltage $\left(V_{\mathrm{g}}\right)$ over the drain-source current $\left(I_{\mathrm{ds}}\right)$. The charge transport properties of the graphene-based SFETs can be analyzed by shifting the Dirac point with various electrolytes. Because of the ambipolar characteristics of graphene, the conductance of the solution-gated graphene channel is modulated by accumulated ions (electrons or holes), causing $n$ - or 
$p$-doping effects in the graphene layer ${ }^{23}$. Moreover, the $I-V$ curves of graphene have a unique "U-shape" because of the ambipolar feature. Based on the Dirac point, the left region has hole conduction, whereas the right region has electron conduction, meaning both the hole and electron influence the graphene conductivity. The characteristics are analyzed by the amount and direction of the shift. As shown in both cases, the graph moves towards the right side when the $\mathrm{pH}$ increases. This indicates that the graphene-based SFET devices become $p$-doped as the $\mathrm{pH}$ increases. The position of the Dirac point indicates the doping state and degree ${ }^{13}$. When the graph moves to the right, a larger positive voltage is needed to reach the Fermi energy level $\left(V_{\mathrm{g}}\right.$ value increases). Applying a positive voltage means driving negative electrons into the system to reach the Fermi energy level, indicating that the system is $p$-doped. Eventually, the $I-V$ curve moves to the right, indicating a higher level of $p$-type doping. Both pristine and Nafion-coated graphene have the same shifting aspects; however, the minimum conductivity variation characteristics are different. It is assumed that the Nafion film prevents charged impurity scattering. In pristine graphene, as the $\mathrm{H}_{3} \mathrm{O}^{+}$concentration increases, the transfer curve shifts to the left, the minimum conductivity decreases, and the width of the minimum conductivity region in $V_{\mathrm{g}}$ becomes wider ${ }^{42-44}$. In contrast, Nafion-coated graphene has a relatively smaller change in minimum conductivity and the width of the minimum conductivity region in $V_{\mathrm{g}}$ is almost identical. However, the parallel shifting of the Dirac point has equivalent results.

Because of the $n$-type doping of glucose, the transfer curves shift to the left as the glucose concentration increases ${ }^{39}$. The Au decoration also exhibits a noticeable difference in the $I-V$ curves. The overall graphs move to the right side ( $p$-type doping), owing to the effects of $\mathrm{Au}$; this is similar to the results of previous studies $^{45-47}$. Also, the $p$-type doping of graphene caused by the $\mathrm{Au}$ ions increases hole concentration, thereby enhancing conductivity ${ }^{46-48}$. The transfer curves move in the same direction as that of pristine graphene, because both cases have $n$-doping effects. It is worth noting that the minimum conductivity decreased for all concentrations of glucose. (The values are negative, indicating that the graph shifts upward when the absolute value of the conductivity decreases.) This is because of the ionic scattering effects caused by the increase in the glucose concentration; previous studies had identical results where the minimum conductivity decreased as the ion concentration increased $^{42,49,50}$. The Au-decorated graphene displays lower minimum conductivity than pristine graphene and the width of the minimum conductivity region in $V_{g}$ becomes broader as the concentration of glucose increases ${ }^{42,49}$. The most significant difference comparing pristine and Au-decorated graphene is that the minimum conductivity value between solutions is distinctively distinguished in the latter case because of the contribution of $\mathrm{Au}$ decoration.

\section{Selectivity tests of Nafion-coated graphene}

As Nafion films selectively allow small cations to penetrate, other cations must be evaluated and compared by the Nafion-coated graphene device (Fig. $6 \mathrm{a}-\mathrm{c}$ ). To set similar conditions, $\mathrm{HCl}, \mathrm{KCl}$, and $\mathrm{NaCl}$ solutions were used for comparison. Previous studies of detecting $\mathrm{K}^{+}$ions using graphene performed the measurements using $\mathrm{KCl}^{51}$. NaCl, in particular, is the primary source of table salt. This evaluation is inevitable for taste-sensing applications because of the selectivity issues. The concentrations of each solution were 1-5 $\mathrm{mM}$ and the measurements were performed in Nafion-coated graphene. As shown in Fig. $6 a-c$, the difference in response is quite noticeable; the response of $\mathrm{H}^{+}$is superior to that of $\mathrm{K}^{+}$and $\mathrm{Na}^{+}$. The response of $\mathrm{H}^{+}$between 1 and $5 \mathrm{mM}$ is much more differentiated than $\mathrm{K}^{+}$and $\mathrm{Na}^{+}$. Also, in the case of $5 \mathrm{mM}, \mathrm{K}^{+}$and $\mathrm{Na}^{+}$have much lower values than that of $\mathrm{H}^{+}$. These results were supported by other studies on Nafion $117^{\circledR}$, which were conducted to analyze the diffusion rate of various cations ${ }^{52}$. Corresponding to our data, the diffusion coefficient of $\mathrm{H}^{+}$is higher than that of $\mathrm{Na}^{+}$and $\mathrm{K}^{+}$, which concludes that the Nafion film selectively penetrates $\mathrm{H}^{+}$ions and $\mathrm{Na}^{+}$or $\mathrm{K}^{+}$ions have lower diffusion rates than $\mathrm{H}^{+}$in Nafion $117^{{ }^{52}}$. Also, Nafion has selectivity for $\mathrm{H}^{+}$ions rather than glucose, uric acid, and ascorbic acid. As these molecules or ions cannot pass through the film, results shown in Fig. $6 \mathrm{~d}-\mathrm{f}$ are reasonable. The exact mechanism of selectively sensing $\mathrm{H}^{+}$ions will be explained later. To summarize the results, the responses to $\mathrm{pH}$, glucose, uric acid, and ascorbic acid of the three SFET types were plotted on a bar graph (Fig. $6 \mathrm{~g}-\mathrm{i})$. The selected values included a $\mathrm{pH}$ of $8.05,5 \mathrm{mM}$ glucose, $5 \mathrm{mM}$ uric acid, and $5 \mathrm{mM}$ ascorbic acid. Pristine graphene can detect all four solutions because of its 2D material characteristics ${ }^{8}$. Nafion-coated graphene selectively detects pH solutions, because it acts as a molecular sieve that prevent large molecules from passing through. Au-decorated graphene facilitates the detection of all the solutions, because it acts as a receptor. However, the response to glucose shows a higher increase compared to the other three solutions.

\section{Responses of the three types of SFETs to real beverages}

In addition to experiments using chemicals, several real beverages were also examined to estimate the potential practical applications of Nafion-coated and Au-decorated graphene. Four different beverages, including orange juice, original coke, Sprite, and zero coke, were used for comparison; the nutrition facts are specified in Supplementary Table 1. For a conspicuous comparison between the beverages, their responses, response times, and base currents were collected from five pulses of each drink tested in this work (Supplementary Figs. 4-6) to conduct PCA for pristine, Nafioncoated, and Au-decorated graphene (Fig. 7a-c). The collected parameters with different scale and units were normalized for a fair comparison. The normalized data were then processed through PCA to yield three principal components and the principal components with the two highest importance were chosen as $x$ - and $y$-axis for 2D plots for the effective selectivity demonstration as shown in Fig. 7a-c. The comparisons were depicted in Fig. 7d-f, showing the sensors exhibited different sensor responses to different beverages. As the contents of Sprite and original coke are similar, the distribution of these two components in PCA plots (green and red) are almost similar in every sample but have different responses as shown in Fig. 7d-f. According to nutrition facts for zero coke, the constituent substances are significantly different from those of the other drinks (no sugars or carbohydrates), resulting in the most distinguishable data points (blue) in PCA plots. Orange juice not only includes carbohydrates but also protein, fats, and vitamin $C$, which influence sensing responses and has the highest response in every case. Also, the sugars from the orange juice is $100 \%$ natural (unsweetened) and the sugars from original coke are highfructose corn syrup as mentioned above. These differences may also influence the results of the response signals of pristine graphene and Au-decorated graphene. From the overall data, our device's capability to detect chemical substances with accompanying PCA analysis can effectively distinguish real drinks that we can access daily.

\section{Illustration of sensing mechanism of the target materials}

The $\mathrm{pH}$ sensing of graphene has a unique mechanism. In the acidic phase, $\mathrm{H}_{3} \mathrm{O}^{+}$ions are dominant, whereas $\mathrm{OH}^{-}$ions are superior in number in the alkali phase, inducing the collection of electrons or holes on the surface of graphene (Fig. 8a). These ions induce capacitive charging on the surface because of the polarized graphene/electrolyte interface. As the adsorption of $\mathrm{H}_{3} \mathrm{O}^{+}$and $\mathrm{OH}^{-}$charges does not transmit across the graphene 
a
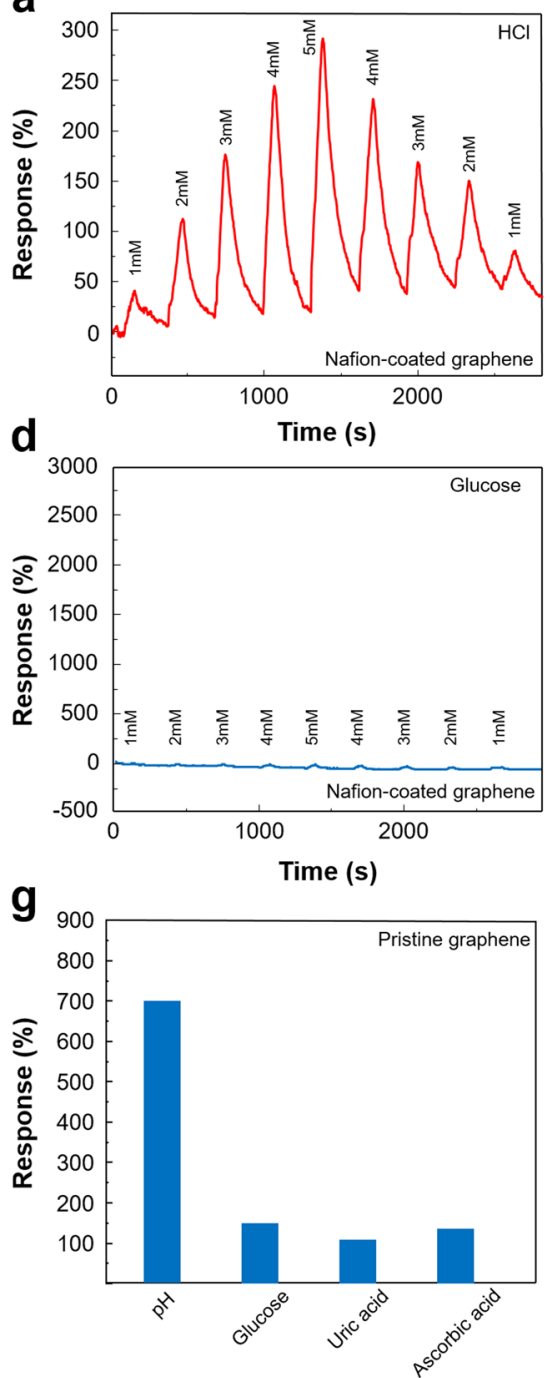

b
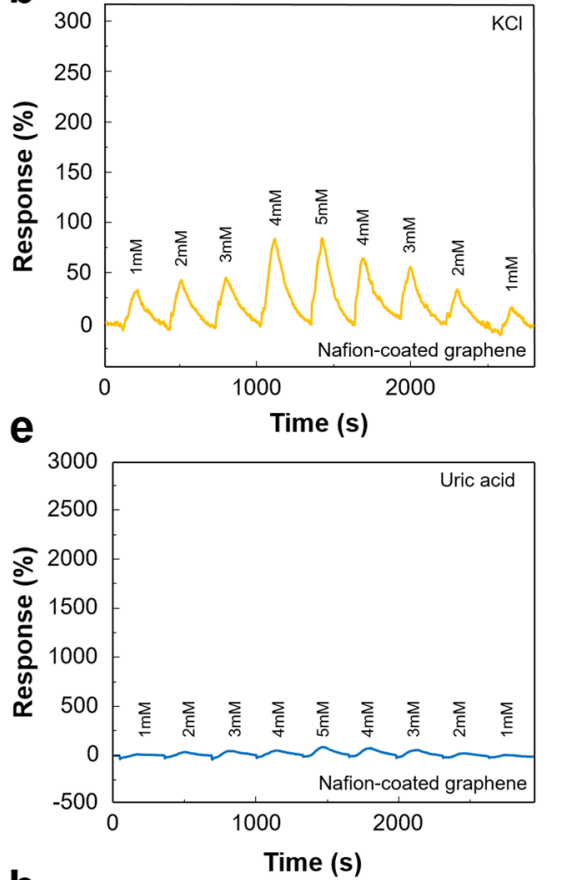

h

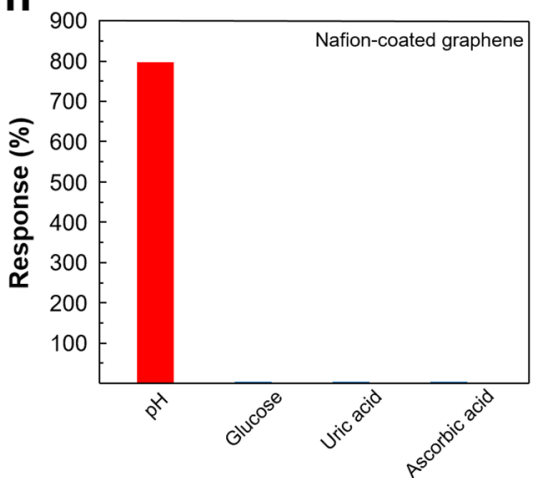

C
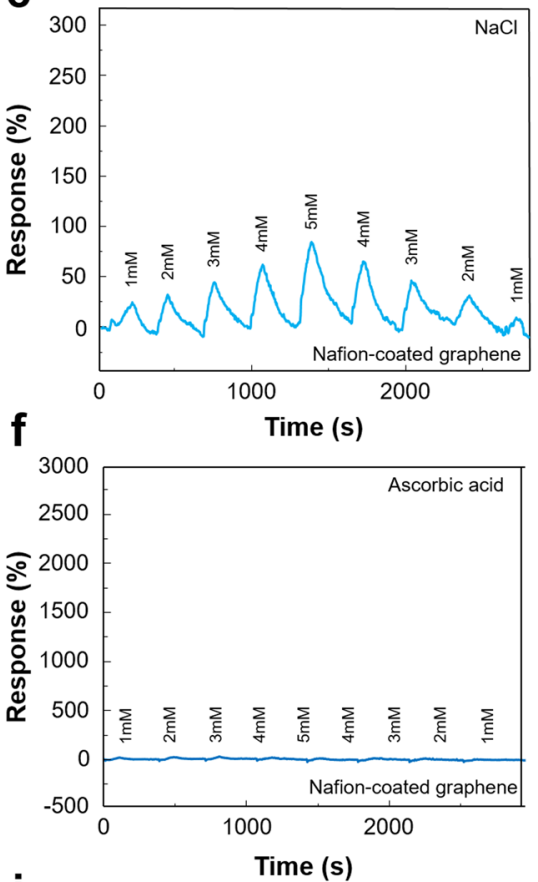

i

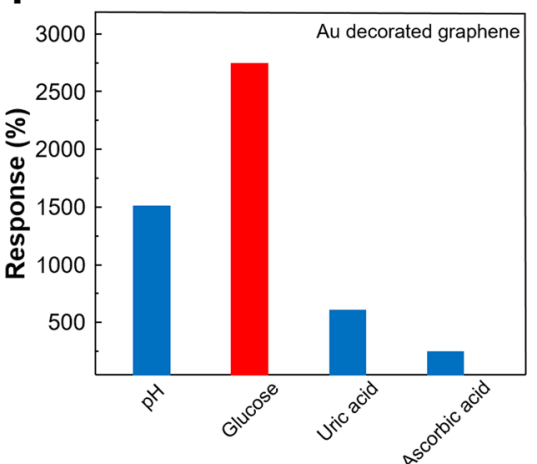

Fig. 6 Selectivity tests of Nafion-coated graphene and results of the three types of SFETs. Selectivity test of Nafion-coated graphene. a HCl, $\mathbf{b} \mathrm{KCl}$, and $\mathbf{c ~ N a C l}$ solutions were tested with identical concentrations of $1-5 \mathrm{mM}$. $\mathbf{d}$ Glucose, $\mathbf{e}$ uric acid, and $\mathbf{f}$ ascorbic acid solutions were also tested to define the selectivity of Nafion-coated graphene. Response results to $\mathrm{pH}(8.05)$, glucose (5 mM), uric acid (5 mM), and ascorbic acid $(5 \mathrm{mM})$ of $\mathbf{g}$ pristine graphene, $\mathbf{h}$ Nafion-coated graphene, and $\mathbf{i}$ Au-decorated graphene.

and solution surface (non-faradaic or capacitive), graphene becomes $n$-doped in $\mathrm{H}_{3} \mathrm{O}^{+}$dominant environments (acidic phase) and $p$-doped in $\mathrm{OH}^{-}$dominant situations (basic phase) ${ }^{26}$. The application of alkali electrolytes to the graphene induces the $\mathrm{OH}^{-}$ ions to attach to the inner Helmholtz plane, whereas acidic electrolyte application induces the $\mathrm{H}_{3} \mathrm{O}^{+}$ions to attach to the plane ${ }^{23}$. As observed, the accumulation of $\mathrm{OH}^{-}$(applying negative gate potential) ions causes a greater conductivity increase than the stacking of $\mathrm{H}_{3} \mathrm{O}^{+}$ions (applying positive gate potential) ${ }^{23}$. Figure $3 a, b$ show that the current level increases as the $\mathrm{pH}$ increases. In Fig. 5a, b, the transfer curves show a shift towards the right as the $\mathrm{pH}$ level becomes increased. In Fig. 5a, b, comparing the conductivity at $V_{\mathrm{g}}=-0.2 \mathrm{~V}$, which was the experimental condition for the real-time sensing curves, the conductivity increased as the $\mathrm{pH}$ value increased. This increase in the conductivity followed by the $\mathrm{pH}$ incline was also observed in the carbon nanotube $\mathrm{pH}$ sensors; this was attributed to the adhesion of hydroxide ions acting as electron scavengers ${ }^{53,54}$.

Among the taste-inducing substances, $\mathrm{H}^{+}$is the smallest in size. The Nafion film prevents the penetration of large molecules or ions but allows the permeation of cations. This is because of the unique ionic transfer mechanism of Nafion. The mechanism is illustrated in Fig. $8 \mathrm{~b}$. In contrast to glucose, $\mathrm{H}^{+}$passes through the Nafion by three methods ${ }^{55}$. The first method is the Grotthuss mechanism ${ }^{56}$, which is the most dominant $\mathrm{H}^{+}$transfer factor. $\mathrm{H}^{+}$ combines with $\mathrm{H}_{2} \mathrm{O}$ forming $\mathrm{H}_{3} \mathrm{O}^{+}$and the proton hops to the adjacent $\mathrm{H}_{2} \mathrm{O}$ molecule. The protons may then move along the surface of the Nafion. The chemical structure of Nafion is roughly divided into hydrophobic and hydrophilic regions. The hydrophilic region is composed of $\mathrm{SO}_{3}{ }^{-}$, which attracts the $\mathrm{H}_{2} \mathrm{O}$ molecules. The $\mathrm{H}_{3} \mathrm{O}^{+}$ion first attaches to $\mathrm{SO}_{3}{ }^{-}$and the proton moves to the adjacent $\mathrm{H}_{2} \mathrm{O}$ molecule and forms a new $\mathrm{H}_{3} \mathrm{O}^{+}$ion, which diffuses to the next $\mathrm{SO}_{3}{ }^{-}$. This process influences the transfer properties. The role of the Nafion film is preventing other conductivity alteration-inducing agents, except for $\mathrm{H}^{+}$rather than increase the $\mathrm{H}^{+}$response using metal decoration or form composites with other materials. Therefore, the sensitivity of Nafion-coated and pristine graphene is almost identical (Fig. 3a, b).

Glucose detection became an emerging issue because of the people diagnosed with diabetes. Consequently, the measurement of the glucose concentration by monitoring blood sugar levels is not unusual ${ }^{57}$. The mechanism of detecting glucose using 

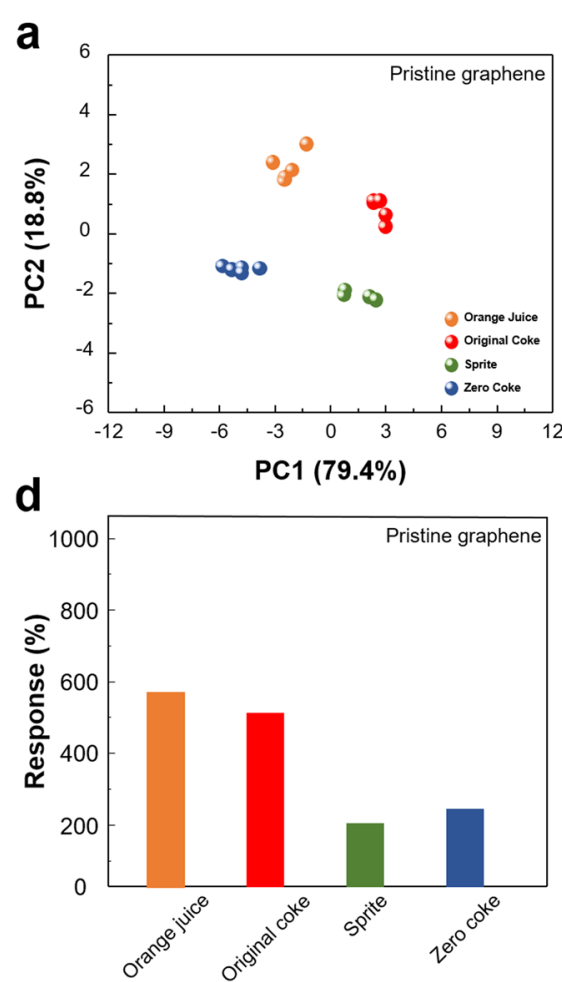

b

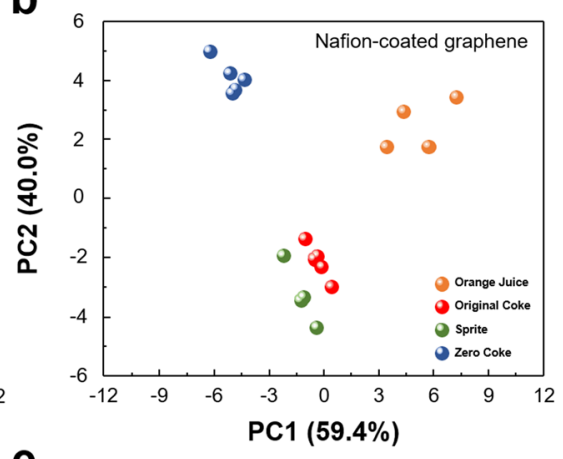

e

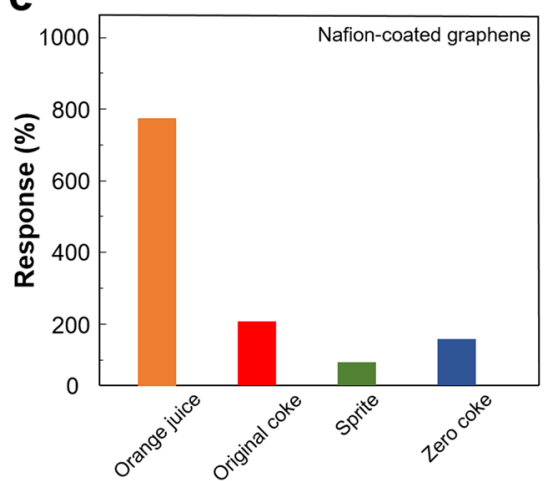

C

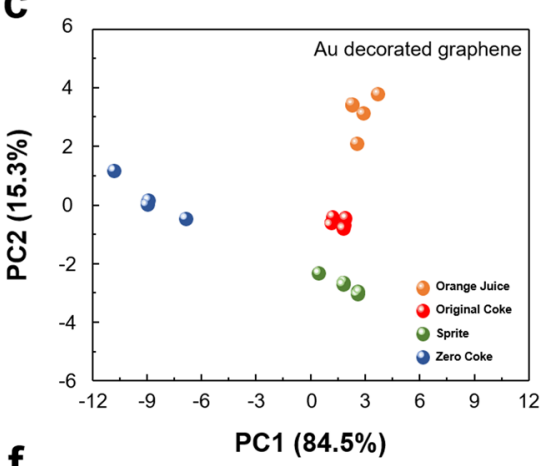

f

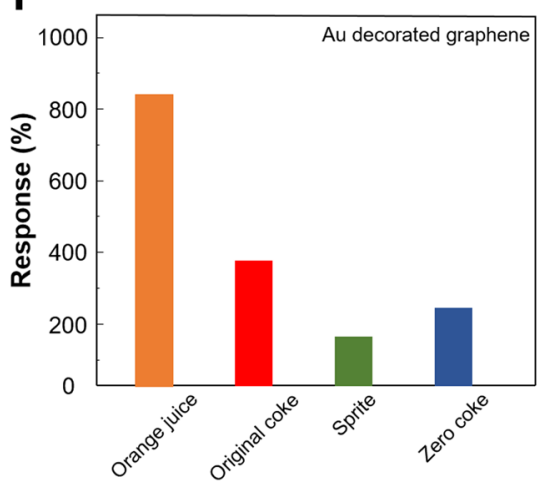

Fig. 7 PCA plots and responses to real beverages of the three types of SFETs. PCA plots and response comparison a, $\mathbf{d}$ pristine graphene, b, e Nafion-coated graphene, and c, f Au-decorated graphene, respectively, to four real beverages (orange juice, original coke, Sprite, and zero coke).

a

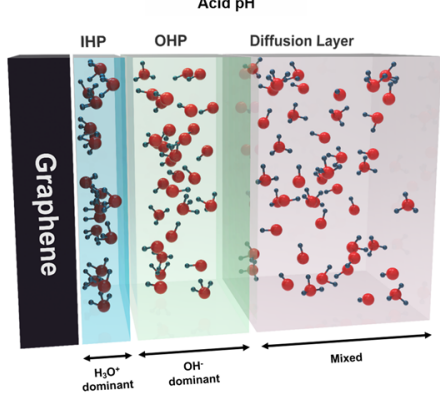

C

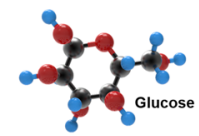

Basic pH

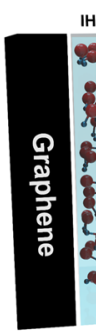

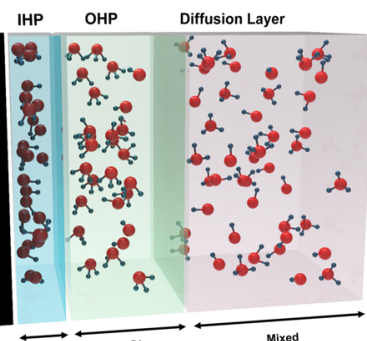

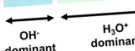

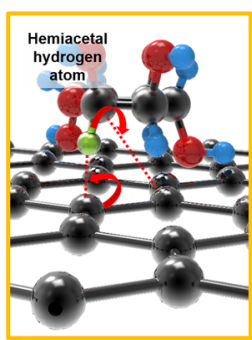
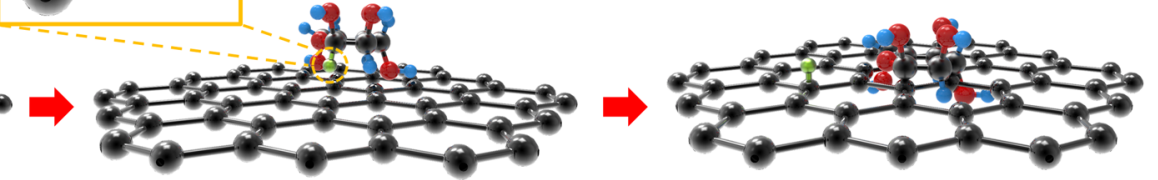

Fig. 8 Schemes illustrating the sensing mechanism of target materials for each type of SFET. a Sensing mechanism of $\mathrm{H}_{3} \mathrm{O}^{+}(\mathrm{acidic} \mathrm{pH})$, $\mathrm{OH}^{-}$(basic $\mathrm{pH}$ ) for graphene. b Sensing mechanism of Nafion-coated graphene selectively detecting $\mathrm{H}_{3} \mathrm{O}^{+}$. c Sensing mechanism of graphene detecting glucose. 
graphene is as follows. In Fig. $8 c$, the glucose attaches to the surface of graphene by losing a hydrogen atom. To explain this phenomenon, Pletcher ${ }^{58}$ proposed a chemisorption model for the adsorption process of glucose to various electrodes. The glucose molecule can be adsorbed to the surface of graphene by abstracting the hemiactalic hydrogen atom from the glucose, forming a bond between the glucose molecule and surface of graphene. The absorbed hydrogen acts as an $n$-type dopant.

Because of its chemical inertness, Au was assumed to be inapplicable as a catalyst. However, Au particles possess remarkable catalytic effects in biosensing when their size is in nanoscales. It should be noted that the Au nanoparticles are highly selective to glucose, from the results in Fig. 4a, b, Supplementary Fig. 4a-d, and Fig. 5c, d. Au-decorated materials become the receptors of glucose ${ }^{59-62}$, thereby enhancing the sensing level and the discrimination availability between glucose and other substances ${ }^{63}$. From the references and our study, it can be concluded that $\mathrm{Au}$ nanoparticles enhance the sensitivity and selectivity to glucose.

\section{DISCUSSION}

We successfully demonstrated a novel ion/molecule sensor based on graphene, which could detect $\mathrm{H}^{+}$or glucose molecules by a one-step method having dynamic on-off functions by the integration of the microfluidic channel. The control of injection and withdrawal of solutions are possible because of the microfluidic channel; leading to the availability of on-off functions in dynamic flow of the solutions. For selective and repetitive detection, Nafion film application or Au nanoparticle decoration were performed on CVD graphene. The Nafion film prevents large molecules and ions from permeating and allows the penetration of only $\mathrm{H}^{+}$, causing selective detection. Conversely, Au nanoparticle decoration allows glucose molecules to attach to the surface of the graphene much more effectively than the other substances working as a receptor, resulting in higher sensitive detection. For practical applications, real beverages, including orange juice, original coke, Sprite, and zero coke, were tested using the fabricated devices and each beverage was differentiated by the PCA plot. A rationally designed graphene channel having dynamic on-off functions possess real-time measurements and high sensitivity/selectivity to ions or dissociated molecules. Furthermore, the simple fabrication process presented a new perspective for the existing solution-gated FET-based ionic and molecular sensors. The microfluidic channel-integrated, graphene-based, solution-gated FET can detect $\mathrm{H}^{+}$, glucose molecules, and real beverages selectively in real time by the dynamic on-off functions, which establishes a precedent for the genuine meaning of taste sensors.

\section{METHODS}

\section{Device preparation}

IDEs were fabricated by the deposition of $\mathrm{Pt} / \mathrm{Ti}$ (thickness of $100 / 30 \mathrm{~nm}$ ) on $\mathrm{SiO}_{2} / \mathrm{Si}$ substrates $\left(\mathrm{SiO}_{2}\right.$ thickness of $\left.300 \mathrm{~nm}\right)$ by an e-beam evaporator, after patterning the process using photolithography. The electrodes were patterned with a distance of $5 \mu \mathrm{m}$ and a size of $1 \mathrm{~mm} \times 1 \mathrm{~mm}$. The patterned IDE substrates were cleaned with acetone and isopropanol via sonication for 20 min and dried in $\mathrm{N}_{2}$ gas.

The graphene samples were grown on $25 \mu \mathrm{m}$-thick copper foil in a quartz tube furnace system via CVD by $\mathrm{CH}_{4}$ and $\mathrm{H}_{2}$ gas. The furnace was heated in vacuum conditions of 90 mTorr without any gas flow for $30 \mathrm{~min}$. The copper foil was preheated at $950^{\circ} \mathrm{C}$ for $30 \mathrm{~min}$ before the growth of the graphene. Hydrogen gas at 35 s.c.c.m. flowed in the furnace under $150 \mathrm{mTorr}$ to obtain a large, single-crystal copper surface. Following the preheating step, a mixture of $\mathrm{CH}_{4}$ and $\mathrm{H}_{2}$ gas at a ratio of $100: 35$ flowed at ambient conditions for $10 \mathrm{~min}$, to synthesize the graphene. The furnace was cooled quickly to room temperature $\left(25^{\circ} \mathrm{C}\right)$ at 35 s.c.c.m. hydrogen gas flow after $10 \mathrm{~min}$ of the graphene growth.
After growing the graphene, poly[methyl methacrylate] (PMMA, $46 \mathrm{mg} /$ $\mathrm{ml}$ in chlorobenzene) was spin-coated on the graphene-coated copper foil. The baking process was then conducted at $180^{\circ} \mathrm{C}$ for $1 \mathrm{~min}$. The opposite side of the copper foil was treated with $\mathrm{O}_{2}$ plasma to etch the graphene on the other side. The sample was immersed in a ferric chloride $\left(1 \mathrm{M} \mathrm{FeCl}_{3}\right)$ bath at room temperature for more than $12 \mathrm{~h}$ to etch away the copper foil. After the etching process, the remaining PMMA-coated graphene on the copper foil was carefully dipped into DI water more than seven times, to remove any redundant etchant. The PMMA-coated graphene was transferred onto the IDE, which was dipped in DI water. PMMA was removed by immersing the substrates at $160^{\circ} \mathrm{C}$ for $2 \mathrm{~h}$, after the PMMA/ graphene layer had adhered entirely to the target substrate.

The graphene samples were divided into three groups; pristine, Nafioncoated, and Au-decorated graphene. Pristine graphene is the sample for comparison of Nafion-coated graphene and Au decorated. Nafion-coated graphene was fabricated by spin-coating Nafion $117^{\circledR}$ on the graphenetransferred IDE. Nafion solution $(0.1 \mathrm{~mL})$ was dropped onto the substrate and then spin-coated at the rate of 2000 r.p.m. for 30 s. The spin-coating rate was chosen as 2000 r.p.m., to prevent other ionic/molecular species from penetrating the Nafion film and letting primary ions to permeate easily through the film. Thick, Nafion-coated membranes (spin-coating rate lower than 2000 r.p.m.) not only blocks other ionic/molecular species but may also hinder fast diffusion of the primary ions to go through the film during the dynamic flow. On the other hand, too thin films (spin-coating rate higher than 2000 r.p.m.) have little difference between the pristine graphene, because primary ions and untargeted ions both react with the surface of the graphene through unintentionally existing pinholes in the film. The response curves and the cross-section SEM image of various spincoated Nafion films are shown in Supplementary Fig. 8. The electrodes were masked with a tape before coating, to prevent the contamination of the source and drain electrodes. Subsequently, the spin-coated samples were dried at $50^{\circ} \mathrm{C}$ for $30 \mathrm{~min}$. Au-decorated graphene was fabricated by electron beam evaporation. The graphene-transferred IDE was covered with a mask exposing only the graphene sites where decoration is needed. The base pressure of the chamber was maintained at $1 \times 10^{-6}$ Torr and the growth rate was $0.1 \AA / \mathrm{s}$ for $100 \mathrm{~s}$, to decorate the graphene with the Au nanoparticles instead of a film. These three samples were merged with the patterned microfluidic channel for the measurements.

A four-inch $\mathrm{SiO}_{2} / \mathrm{Si}$ wafer was cleaned with acetone and isopropanol via sonication of $20 \mathrm{~min}$ and dried with $\mathrm{N}_{2}$ gas to form a patterned substrate for the fabrication of the microfluidic channel. The adhesion layer was formed by spin-coating SU-8 2 on the wafer at 3000 r.p.m. for 30 s. The soft baking process was then conducted at $65^{\circ} \mathrm{C}$ for $2 \mathrm{~min}$ and at $95^{\circ} \mathrm{C}$ for $2 \mathrm{~min}$. After soft baking, a UV lamp was exposed for $2 \mathrm{~min}$. Finally, hard baking was performed at $180^{\circ} \mathrm{C}$ for $3 \mathrm{~min}$. For the photoresist layer, SU-8 50 was spin-coated for $3 \mathrm{~min}$ in 2000 r.p.m. It was then soft-baked at $65^{\circ} \mathrm{C}$ for $5 \mathrm{~h}$ and at $95^{\circ} \mathrm{C}$ for $5 \mathrm{~h}$. It was exposed in a UV lamp for $30 \mathrm{~s}$, followed by a hard baking process at $180^{\circ} \mathrm{C}$ for $3 \mathrm{~min}$. It was then developed for 3 min, rinsed with DI water, and dried with $\mathrm{N}_{2}$ gas.

The microfluidic channel device was fabricated by adhering the channelpatterned PDMS to the three different graphene samples, which were on the IDE. The channel-patterned PDMS was fabricated using a conventional PDMS replica molding technique. An SU-8 2075 (Microchem Corp.) master template with a thickness of $100 \mu \mathrm{m}$ and a width of 500,800 , and $1000 \mu \mathrm{m}$ was prepared as a mold by conventional photolithography. A mixture of the PDMS monomer and curing agent in the weight ratio of 10:1 (Sylgard 184) was poured onto the SU-8 master template and degassed in a vacuum chamber. After curing for $1 \mathrm{~h}$ at $80^{\circ} \mathrm{C}$, the patterned microfluidic channel was cut with a razor and detached. For the stable adhesion between the channel-patterned PDMS and the IDE, the former with acrylic transfer tape (Samchun Chemicals) was exposed to oxygen plasma with a plasma power of $125 \mathrm{~W}$, plasma time of $120 \mathrm{~s}$, and flow rate of oxygen at 60 s.c.c.m. After placing Cu wires on the source, the drain electrodes of the IDE and PDMS were attached.

\section{Characterization}

The thickness of the Nafion-spin-coated samples were evaluated using field-emission SEM (Merlin Compact), with an acceleration voltage of $5 \mathrm{kV}$ and a working distance of $8.8 \mathrm{~mm}$. The morphologies of the pristine and Au-decorated graphene were characterized using field-emission TEM (JEM$2100 F$, JEOL). Bright-field and high-resolution images were obtained by TEM; EDS analysis was then performed. Raman spectroscopy (LabRAM HR Evolution) was used to investigate the existence of graphene. 


\section{Material preparation}

The $\mathrm{pH}$ solutions were obtained by mixing $\mathrm{KH}_{2} \mathrm{PO}_{4}$ powders (Daejung, 99\%) and $\mathrm{K}_{2} \mathrm{HPO}_{4}$ (Junsei, 99\%) at various ratios for each $\mathrm{pH}$ value, mixing with $\mathrm{DI}$ water. $\mathrm{NaCl}$ powder (Daejung, 99.5\%) and $\mathrm{KCl}$ powder (Daejung, 99\%) were dissolved in DI water to obtain solutions with concentrations of 1-5 mM solutions. $\mathrm{HCl}$ (Daejung, 35.4\%) solutions were diluted to produce concentrations of $1-5 \mathrm{mM}$. The glucose powder was purchased from Sigma-Aldrich and then mixed with $\mathrm{NaOH}$ solutions. The $\mathrm{NaOH}$ solutions were prepared using $\mathrm{NaOH}$ beads (Daejung) dissolved in DI water, with a concentration of $0.1 \mathrm{M}$. Uric acid (Sigma-Aldrich, 99\%) and L(+) ascorbic acid (Junsei, 99.6\%) were mixed with $\mathrm{NaOH}$ solutions in conditions identical to those of glucose. The beverages used were orange juice, original coke, Sprite, and zero coke. The nutrition contents are stated in Supplementary Table 1. Also, the carbonated drinks were poured to a vial and covered up with parafilm. The parafilm cover was punched with holes and left for a few days to release carbonic acid gas from the drink. The gas dissolved in the drink hinders the measurement by producing noise. The Nafion $117^{\circledR}$ solutions was purchased from Sigma-Aldrich.

\section{Ion/molecule measurements}

Two syringe pumps (Pump 11 Elite Infusion/Withdrawal Programmable Dual Syringe) were used for the base solution injection and withdrawal, respectively (Supplementary Fig. 2). The flow velocity was $0.07 \mathrm{~mL} / \mathrm{min}$ and when the target solution was injected using a pipet $(100 \mu \mathrm{L})$, the infusion pump was paused (withdrawal pump kept working). Response tests were carried out at various volumes $(50,75,100$, and $125 \mu \mathrm{L}$ ) of the same concentration solutions for optimization. The volume of the solution does not influence the response value significantly; however, the duration is longer because of the amount (Supplementary Fig. 9). The infusion pump was resumed for $100 \mathrm{~s}, 200 \mathrm{~s}$ after the target solution injection. The cycle of each solution was $300 \mathrm{~s}$. A Pt wire was inserted through the hole and contacted with a gate source. The electrical properties of the device were evaluated using an Agilent $4156 \mathrm{C}$ semiconductor analyzer in source-drain voltage of $0.1 \mathrm{~V}$ and the gate voltage of $-0.2 \mathrm{~V}$.

The response of the sensing device is defined as follows:

Response(\%) $=\frac{I_{t}-I_{0}}{I_{0}} \times 100 \%=\frac{\Delta l}{I_{0}} \times 100 \%$

where $I_{\mathrm{t}}$ and $I_{0}$, respectively, represent the electrical conductivity of the sensor in the presence of the target solution and base solution, respectively.

\section{DATA AVAILABILITY}

The data of this study are available from the corresponding author upon reasonable request.

Received: 24 November 2020; Accepted: 12 March 2021; Published online: 12 April 2021

\section{REFERENCES}

1. Mastroianni, B. Cooking at Home More During COVID-19? What to Know About Food Safety, https://www.healthline.com/health-news/cooking-at-home-moreduring-covid-19-what-to-know-about-food-safety (2020).

2. Riul, A. Jr., Dantas, C. A., Miyazaki, C. M. \& Oliveria, O. N. Jr. Recent advances in electronic tongues. Analyst 135, 2481-2495 (2010).

3. Habara, M., Ikezaki, H. \& Toko, K. Study of sweet taste evaluation using taste sensor with lipid/polymer membranes. Biosens. Bioelectron. 19, 1559-1563 (2004).

4. Parra, V. et al. E-tongue based on a hybrid array of voltammetric sensors based on phthalocyanines, perylene derivatives and conducting polymers: discrimination capability towards red wines elaborated with different varieties of grapes. Sens. Actuators B Chem. 115, 54-61 (2006).

5. Pigani, L. et al. Classification of red wines by chemometric analysis of voltammetric signals from PEDOT-modified electrodes. Anal. Chim. Acta 643, 67-73 (2009).

6. Medeiros, E. S., Gregório, R., Martinez, R. A. \& Mattoso, L. H. A taste sensor array based on polyaniline nanofibers for orange juice quality assessment. Sens. Lett. 7, 24-30 (2009).

7. Borato, C. E., Leite, F. L., Oliveira, O. N. \& Mattoso, L. H. Efficient taste sensors made of bare metal electrodes. Sens. Lett. 4, 155-159 (2006).

8. Lee, C. W., Suh, J. M. \& Jang, H. W. Chemical sensors based on 2-Dimensional materials for selective detection of ions and molecules in liquid. Front. Chem. 7, 708 (2019).
9. Hasani, A. et al. Recent progress of two-dimensional materials and metal-organic framework-based taste sensors. J. Korean Ceram. Soc. 57, 353-367 (2020).

10. Anichini, C. et al. Chemical sensing with 2D materials. Chem. Soc. Rev. 47, 4860-4908 (2018).

11. Novoselov, K. S. et al. Two-dimensional atomic crystals. PNAS 102, 10451-10453 (2005).

12. Meric, I. et al. Current saturation in zero-bandgap, top-gated graphene field-effect transistors. Nat. Nanotechnol. 3, 654-659 (2008).

13. Schwierz, F. Graphene transistors. Nat. Nanotechnol. 5, 487 (2010),

14. Tang, Y., Zhen, L., Liu, J. \& Wu, J. Rapid antibiotic susceptibility testing in a microfluidic pH sensor. Anal. Chem. 85, 2787-2794 (2013).

15. Läritz, C. \& Pagel, L. A microfluidic pH-regulation system based on printed circuit board technology. Sens. Actuator A Phys. 84, 230-235 (2000).

16. Jeon, J. M. et al. Microscopic evidence for strong interaction between $\mathrm{Pd}$ and graphene oxide that results in metal-decoration-induced reduction of graphene oxide. Adv. Mater. 29, 1605929 (2017).

17. Malard, L. M., Pimenta, M. A., Dresselhaus, G. \& Dresselhaus, M. S. Raman spectroscopy in graphene. Phys. Rep. 473, 51-87 (2009).

18. Mailly-Giacchetti, B. et al. pH sensing properties of graphene solution-gated fieldeffect transistors. J. Appl. Phys. 114, 084505 (2013).

19. Rümmeli, M. H. et al. Direct low-temperature nanographene CVD synthesis over a dielectric insulator. ACS Nano 4, 4206-4210 (2010).

20. Passos, R. R., Paganin, V. A. \& Ticianelli, E. A. Studies of the performance of PEM fuel cell cathodes with the catalyst layer directly applied on Nafion membranes. Electrochim. Acta 51, 5239-5245 (2006).

21. Lee, Z. et al. Direct imaging of soft-hard interfaces enabled by graphene. Nano Lett. 9, 3365-3369 (2009).

22. Qin, Y. et al. Integrated water quality monitoring system with $\mathrm{pH}$, free chlorine, and temperature sensors. Sens. Actuators B Chem. 255, 781-790 (2018).

23. Ang, P. K., Chen, W., Wee, A. T. S. \& Loh, K. P. Solution-gated epitaxial graphene as pH sensor. J. Am. Chem. Soc. 130, 14392-14393 (2008).

24. Xie, G. \& Okada, T. Water transport behavior in Nafion 117 membranes. J. Electrochem. Soc. 142, 3057 (1995).

25. Ippolito, S. J., Kandasamy, S., Kalantar-Zadeh, K. \& Wlodarski, W. Hydrogen sensing characteristics of WO3 thin film conductometric sensors activated by Pt and Au catalysts. Sens. Actuators B Chem. 108, 154-158 (2005).

26. Lei, N., Li, P., Xue, W. \& Xu, J. Simple graphene chemiresistors as $\mathrm{pH}$ sensors: fabrication and characterization. Meas. Sci. Technol. 22, 107002 (2011).

27. Ohno, Y., Maehashi, K., Yamashiro, Y. \& Matsumoto, K. Electrolyte-gated graphene field-effect transistors for detecting $\mathrm{pH}$ and protein adsorption. Nano Lett. 9, 3318-3322 (2009).

28. Park, H. J., Yoon, J. H., Lee, K. G. \& Choi, B. G. Potentiometric performance of flexible $\mathrm{pH}$ sensor based on polyaniline nanofiber arrays. Nano Converg. 6, 9 (2019).

29. Yoon, J. H. et al. High performance flexible $\mathrm{pH}$ sensor based on polyaniline nanopillar array electrode. J. Colloid Interface Sci. 490, 53-58 (2017).

30. Manjakkal, L., Szwagierczak, D. \& Dahiya, R. Metal oxides based electrochemical pH sensors: current progress and future perspectives. Prog. Mater. Sci. 109, 100635 (2020).

31. Reach, G. \& Wilson, G. S. Can continuous glucose monitoring be used for the treatment of diabetes. Anal. Chem. 64, 381A-386A (1992).

32. Liang, T. et al. Rising mesopores to realize direct electrochemistry of glucose oxidase toward highly sensitive detection of glucose. Adv. Funct. Mater. 29, 1903026 (2019).

33. Skopp, J. Derivation of the Freundlich adsorption isotherm from kinetics. J. Chem. Educ. 86, 1341 (2009).

34. Xuan, X., Yoon, H. S. \& Park, J. Y. A wearable electrochemical glucose sensor based on simple and low-cost fabrication supported micro-patterned reduced graphene oxide nanocomposite electrode on flexible substrate. Biosens. Bioelectron. 109, 75-82 (2018).

35. Luo, J., Jiang, S., Zhang, H., Jiang, J. \& Liu, X. A novel non-enzymatic glucose sensor based on $\mathrm{Cu}$ nanoparticle modified graphene sheets electrode. Anal. Chim. Acta 709, 47-53 (2012).

36. Wang, Y., Shao, Y., Matson, D. W., Li, J. \& Lin, Y. Nitrogen-doped graphene and its application in electrochemical biosensing. ACS Nano 4, 1790-1798 (2010).

37. $\mathrm{Wu}, \mathrm{H}$. et al. Glucose biosensor based on immobilization of glucose oxidase in platinum nanoparticles/graphene/chitosan nanocomposite film. Talanta $\mathbf{8 0}$, 403-406 (2009).

38. Shan, C. et al. Graphene/AuNPs/chitosan nanocomposites film for glucose biosensing. Biosens. Bioelectron. 25, 1070-1074 (2010).

39. Kwak, Y. H. et al. Flexible glucose sensor using CVD-grown graphene-based field effect transistor. Biosens. Bioelectron. 37, 82-87 (2012).

40. Zhang, Y., Wang, Y., Jia, J. \& Wang, J. Nonenzymatic glucose sensor based on graphene oxide and electrospun $\mathrm{NiO}$ nanofibers. Sens. Actuators B Chem. 171, 580-587 (2012). 
41. Jiang, D. et al. Enhanced non-enzymatic glucose sensing based on copper nanoparticles decorated nitrogen-doped graphene. Biosens. Bioelectron. 54, 273-278 (2014).

42. Adam, S., Hwang, E., Galitski, V. \& Sarma, S. D. A self-consistent theory for graphene transport. PNAS 104, 18392-18397 (2007).

43. Newaz, A., Puzyrev, Y. S., Wang, B., Pantelides, S. T. \& Bolotin, K. I. Probing charge scattering mechanisms in suspended graphene by varying its dielectric environment. Nat. Commun. 3, 1-6 (2012).

44. Chen, J.-H. et al. Charged-impurity scattering in graphene. Nat. Phys. 4, 377-381 (2008).

45. Krajewska, A. et al. Influence of Au doping on electrical properties of CVD graphene. Carbon 100, 625-631 (2016).

46. Benayad, A. et al. Controlling work function of reduced graphite oxide with Auion concentration. Chem. Phys. Lett. 475, 91-95 (2009).

47. Shi, Y. et al. Work function engineering of graphene electrode via chemical doping. ACS Nano 4, 2689-2694 (2010).

48. Chen, L. et al. Field emission performance enhancement of Au nanoparticles doped graphene emitters. Appl. Phys. Lett. 103, 233105 (2013).

49. Xiao, S., Chen, J.-H., Adam, S., Williams, E. D. \& Fuhrer, M. S. Charged impurity scattering in bilayer graphene. Phys. Rev. B 82, 041406 (2010).

50. Chen, F., Xia, J. \& Tao, N. lonic screening of charged-impurity scattering in graphene. Nano Lett. 9, 1621-1625 (2009).

51. He, R. X. et al. Solution-gated graphene field effect transistors integrated in microfluidic systems and used for flow velocity detection. Nano Lett. 12 1404-1409 (2012).

52. Stenina, I. A., Sistat, P., Rebrov, A., Pourcelly, G. \& Yaroslavtsev, A. B. Ion mobility in Nafion-117 membranes. Desalination 170, 49-57 (2004).

53. Lee, K. et al. $\mathrm{pH}$ sensitive multiwalled carbon nanotubes. Mater. Lett. 61 3201-3203 (2007).

54. Pan, H., Feng, Y. P. \& Lin, J. Y. Ab initio study of $\mathrm{OH}$-functionalized single-wall carbon nanotubes. Phys. Rev. B 70, 245425 (2004).

55. Choi, P., Jalani, N. H. \& Datta, R. Thermodynamics and proton transport in nafion: II. Proton diffusion mechanisms and conductivity. J. Electrochem. Soc. 152, E123 (2005).

56. Agmon, N. The grotthuss mechanism. Chem. Phys. Lett. 244, 456-462 (1995).

57. Anderson, B., Ho, J., Brackett, J., Finkelstein, D. \& Laffel, L. Parental involvement in diabetes management tasks: relationships to blood glucose monitoring adherence and metabolic control in young adolescents with insulin-dependent diabetes mellitus. J. Pediatr. 130, 257-265 (1997).

58. Pletcher, D. Electrocatalysis: present and future. J. Appl. Electrochem. 14, 403-415 (1984).

59. Biella, S., Prati, L. \& Rossi, M. Selective oxidation of D-glucose on gold catalyst. J. Catal. 206, 242-247 (2002)

60. Comotti, M., Della Pina, C., Matarrese, R. \& Rossi, M. The catalytic activity of "naked" gold particles. Angew. Chem. Int. Ed. 43, 5812-5815 (2004).

61. Mirescu, A. \& Prüße, U. Selective glucose oxidation on gold colloids. Catal. Commun. 7, 11-17 (2006)

62. Megías-Sayago, C., Ivanova, S., López-Cartes, C., Centeno, M. \& Odriozola, J. A. Gold catalysts screening in base-free aerobic oxidation of glucose to gluconic acid. Catal. Today 279, 148-154 (2017).

63. Chen, L. Y., Fujita, T., Ding, Y. \& Chen, M. W. A three-dimensional gold-decorated nanoporous copper core-shell composite for electrocatalysis and nonenzymatic biosensing. Adv. Funct. Mater. 20, 2279-2285 (2010).

64. Cheng, Z., Li, Q., Li, Z., Zhou, Q. \& Fang, Y. Suspended graphene sensors with improved signal and reduced noise. Nano Lett. 10, 1864-1868 (2010).

65. Kwon, S. S. et al. Reversible and irreversible responses of defect-engineered graphene-based electrolyte-gated pH sensors. ACS Appl. Mater. Interfaces 8, 834-839 (2016)

66. Zhu, Y. et al. A solid dielectric gated graphene nanosensor in electrolyte solutions. Appl. Phys. Lett. 106, 123503 (2015).
67. Huang, Y. et al. Nanoelectronic biosensors based on CVD grown graphene. Nanoscale 2, 1485-1488 (2010).

\section{ACKNOWLEDGEMENTS}

We thank Iljin Materials Co., Ltd for supporting this study by providing high-quality graphene samples and the Institute of Engineering Research at Seoul National University for providing the research facilities for this work. This work was financially supported by the Basic Science Research Program (2017R1A2B3009135, 2020R1A2B5B03002154), Nano-Material Technology Development Program (2016M3A7B4910), Nuclear Energy R\&D Program (2020M2D8A206983011), Korea Government Ministry of Science and ICT (MSIT) (2019M3E6A1103818, 2021R1A2B5B03001851) and Future Material Discovery Program (2016M3D1A1027666, 2018M3D1A1058793) through the National Research Foundation of Korea.

\section{AUTHOR CONTRIBUTIONS}

C.W.L. and J.M.S. designed the experiments. C.W.L. performed the experiments. S.C. and A.E.J. transferred the CVD graphene onto the IDE substrate. T.H.L. characterized pristine and Au-decorated graphene samples by TEM. J.W.Y. and S.A.L. characterized Nafion-coated graphene using SEM. D.Y. conducted the microfluidic channel using the PDMS replica molding technique. C.W.L. and J.M.S. analyzed the data. C.W.L. wrote the manuscript. C.W.L. and H.W.J. conceived this work. H.W.J., K.D.S., and S.Y.K. revised the finalized manuscript.

\section{COMPETING INTERESTS}

The authors declare no competing interests.

\section{ADDITIONAL INFORMATION}

Supplementary information The online version contains supplementary material available at https://doi.org/10.1038/s41699-021-00223-2.

Correspondence and requests for materials should be addressed to S.Y.K., D.S.K. or H.W.J.

Reprints and permission information is available at http://www.nature.com/ reprints

Publisher's note Springer Nature remains neutral with regard to jurisdictional claims in published maps and institutional affiliations.

Open Access This article is licensed under a Creative Commons Attribution 4.0 International License, which permits use, sharing, adaptation, distribution and reproduction in any medium or format, as long as you give appropriate credit to the original author(s) and the source, provide a link to the Creative Commons license, and indicate if changes were made. The images or other third party material in this article are included in the article's Creative Commons license, unless indicated otherwise in a credit line to the material. If material is not included in the article's Creative Commons license and your intended use is not permitted by statutory regulation or exceeds the permitted use, you will need to obtain permission directly from the copyright holder. To view a copy of this license, visit http://creativecommons. org/licenses/by/4.0/.

(c) The Author(s) 2021 